NBER WORKING PAPER SERIES

\title{
WHAT DO EMPLOYEE REFERRAL PROGRAMS DO? MEASURING THE DIRECT AND OVERALL EFFECTS OF A MANAGEMENT PRACTICE
}

\author{
Guido Friebel \\ Matthias Heinz \\ Mitchell Hoffman \\ Nick Zubanov \\ Working Paper 25920 \\ http://www.nber.org/papers/w25920 \\ NATIONAL BUREAU OF ECONOMIC RESEARCH \\ 1050 Massachusetts Avenue \\ Cambridge, MA 02138 \\ June 2019, Revised August 2022
}

We thank Heski Bar-Isaac, Nick Bloom, Tore Ellingsen, Matt Gentzkow, Mark Granovetter, Maria Guadalupe, Michael Kosfeld, Edward Lazear, Rosario Macera, Kathryn Shaw, Chad Syverson, John Van Reenen, Russell Weinstein, and especially Lowell Taylor for their comments and suggestions. We are grateful to the World Management Survey (WMS) and especially Daniela Scur for sharing summary statistics on the prevalence of employee referral programs. We thank the study firm's management and employees for their collaboration. We thank numerous seminar and conference participants for their feedback. We thank Muhammad Azim, Daphnle Baldassari, Griffin Cai, Julija Mozureviciute, Monika Mozureviciute, Mariana Osegura, Sonja Settele, and Julia Wang for excellent research assistance. Financial support from the Deutsche Forschungsgemeinschaft (DFG, German Research Foundation) under Germany's Excellence Strategy (EXC 2126/1- 390838866), Michael Lee-Chin Family Institute, and SSHRC is gratefully acknowledged. The experiment was pre-registered on 11/23/2015 with the AEA RCT registry under ID AEARCTR-0000964. The views expressed herein are those of the authors and do not necessarily reflect the views of the National Bureau of Economic Research.

NBER working papers are circulated for discussion and comment purposes. They have not been peerreviewed or been subject to the review by the NBER Board of Directors that accompanies official NBER publications.

(C) 2019 by Guido Friebel, Matthias Heinz, Mitchell Hoffman, and Nick Zubanov. All rights reserved. Short sections of text, not to exceed two paragraphs, may be quoted without explicit permission provided that full credit, including $\odot$ notice, is given to the source. 
What Do Employee Referral Programs Do? Measuring the Direct and Overall Effects of a Management Practice

Guido Friebel, Matthias Heinz, Mitchell Hoffman, and Nick Zubanov

NBER Working Paper No. 25920

June 2019, Revised August 2022

JEL No. D23,M51,M52

\title{
ABSTRACT
}

Employee referral programs (ERPs) are randomly introduced in a grocery chain. On direct effects, larger referral bonuses increase referral quantity but decrease quality, though the increase in referrals from ERPs is modest. However, the overall effect of having an ERP is substantial, reducing attrition by $15 \%$ and significantly decreasing labor costs. This occurs, partly, because referrals stay longer than non-referrals, but, mainly, from indirect effects: non-referrals stay longer in treated than in control stores. The most-supported mechanism for these indirect effects is workers value being involved in hiring. Attrition impacts are larger in higher-performing stores and better local labor markets.

\author{
Guido Friebel \\ Goethe University Frankfurt \\ and CEPR \\ gfriebel@wiwi.uni-frankfurt.de \\ Matthias Heinz \\ University of Cologne \\ Department of Economics \\ Albertus-Magnus-Platz \\ 50923 Köln \\ Germany \\ heinz@wiso.uni-koeln.de
}

\author{
Mitchell Hoffman \\ Rotman School of Management \\ University of Toronto \\ 105 St. George Street \\ Toronto, ON M5S 3E6 \\ and NBER \\ mitchell.hoffman@ rotman.utoronto.ca \\ Nick Zubanov \\ Konstanz University \\ nick.zubanov@uni-konstanz.de
}

A data appendix is available at http://www.nber.org/data-appendix/w25920

A randomized controlled trials registry entry is available at https://www.socialscienceregistry.org/trials/964 
Management practices are widely held to matter for firm performance (Ichniowski et al., 1997; Ichniowski \& Shaw, 1999; Bloom \& Van Reenen, 2007; Syverson, 2011). In addition to the rich, growing body of work on the overall quality of a firm's management practices, scholars are increasingly interested in the impact of particular practices and how they matter.

An important area where management practices are understudied is firm hiring (Oyer \& Schaefer, 2011), which is surprising given that hiring is believed critical for firm performance (Bloom \& Reenen, 2011). One of the most common ways by which workers get hired is via employee referrals. ${ }^{1}$ As surveyed by Topa (2019), while most work on referrals analyzes the perspective of job-seekers (e.g., Granovetter, 1974; Bayer et al., 2008), a smaller stream of work analyzes referrals from the perspective of firms, showing that referral hires tend to be of higher quality than non-referrals, with lower turnover, lower recruiting costs, and sometimes higher productivity (Brown et al., 2016; Burks et al., 2015). Thus, it is unsurprising that many firms have employee referral programs (ERPs), a management practice where workers are explicitly encouraged to refer their social contacts for jobs, often using bonuses. ${ }^{2}$

Despite the prevalence of ERPs, that many firms use a management practice does not necessarily imply that it is valuable (Blader et al., 2020; DellaVigna \& Gentzkow, 2019). What do ERPs do and why? Beyond a possible role in hiring good workers, can ERPs provide firms with other benefits (or costs)? We address these questions using a 13-month randomized controlled trial (RCT) on over 10,000 workers in a large European grocery chain, followed by the immediate rollout of an ERP to the entire firm. Our paper is the first RCT on ERPs in a for-profit firm. To our knowledge, it is also the first, large-scale, within-the-firm $\mathrm{RCT}$ on any hiring procedure, a point we contextualize further below.

All the firm's 238 stores were randomly assigned to Control (no ERP) or one of four ERP treatment arms inviting referrals. One arm only provided information to encourage referrals. The other three arms additionally paid different referral bonuses of up to $40 \%$ of monthly salary after taxes if the referrer and the "referral" stayed at least 5 months. ${ }^{3}$

As can be asked for many management practices, there are two key conceptual ques-

\footnotetext{
${ }^{1}$ Roughly $25-40 \%$ of European jobs and about half of US jobs are found via networks (Topa, 2011). Referrals may matter for many features of labor markets, e.g., wage inequality (Montgomery, 1991).

${ }^{2}$ A wide range of firms use ERPs, including AT\&T, Starbucks, UPS, Deutsche Bahn, IKEA, PWC, Walmart, Enterprise Rent-a-Car, Booking.com, and Google (see https://drive.google.com/file/d/ 1Hu7GA-XI6oWD-xtnD3f82Y2WenE3_ZjM/view). The Society for Human Resource Management defines an ERP as "a recruiting strategy in which employers encourage current employees, through rewards, to refer qualified candidates for jobs in their organizations" (SHRM, 2016). CareerBuilder.com (2012) estimated that $69 \%$ of firms on its platform had a formal ERP. In the retail module of the World Management Survey (Bloom \& Van Reenen, 2007) covering Canada, US, and UK, $23 \%$ of establishments have an ERP (see Appendix A.1 for details and discussion). ReferralPrograms.org (2017) reports that $82 \%$ of firms use cash bonuses in their ERP, $2 \%$ use donations, $7 \%$ use experiences, and $9 \%$ use no reward.

${ }^{3}$ As in past work, we use "referral" both for the recommendation process and for the person hired.
} 
tions regarding ERPs. First, what are the direct effects, i.e., effects on the targeted worker behavior? That is, what is the impact of ERPs — both their existence and the bonus level —on generating employee referrals, as well as the quality of referral hires? This includes assessing whether referrals are of higher quality than non-referrals and whether this quality advantage varies with the bonus offered. Second, what are the overall effects of ERPs, i.e., what is the total impact of having an ERP on worker and firm outcomes? Overall effects are assessed among all workers, including incumbent workers and non-referred new hires. If having an ERP provides a positive signal to workers (e.g., that the firm respects its workers (Ellingsen \& Johannesson, 2008; Rebitzer \& Taylor, 2011) and trusts them not to make bad referrals) or a negative one (e.g., that the firm needs its workers' help in recruiting new workers), then overall effects may diverge sharply from direct effects.

By randomizing both the structure and existence of ERPs across stores, we designed the RCT to assess both direct and overall effects of ERPs. Beyond the large sample size it offers, the particular firm we study (described more in Section 2) is well-suited for the RCT. First, because of high worker turnover, grocery stores are constantly looking for new workers. Second, grocery cashier jobs have minimal qualifications, so everyone's friends could reasonably be hired. Third, the firm was willing to have workers and managers take a series of detailed surveys. In addition to being helpful for the RCT, the first two of these characteristics are common to many low-skilled jobs worldwide. The retail setting of the firm is also broadly representative of many jobs.

Section 3 shows that the direct effects of ERPs are directionally as expected. Higher bonuses lead to more referrals. However, while statistically significant, the magnitude of the impacts seems relatively small. Even under the largest bonus, only $5 \%$ of hires are referrals. Encouraging referrals without using a bonus leads to no referrals. We believe the seemingly low referral rate reflects (1) we are studying formal instead of informal referrals and (2) grocery jobs are perceived as unattractive, a point supported by surveys. While the number of referrals is modest, referral quality is high: referrals have $45 \%$ lower attrition than observably similar non-referrals and are $19 \%$ less likely to be absent, though the absence difference is not statistically significant. However, as bonuses increase, the relative retention benefit of referrals falls.

Section 4 turns to overall effects, and provides the paper's quantitatively most important result: having an ERP in a store leads to a roughly $15 \%$ reduction in worker turnover. Effects persist throughout the RCT, and are sizable for both new workers and workers hired prior to the RCT. These effects cannot be mainly attributed to the incidence of referrals or to peer effects because turnover falls in treatment stores where no RCT referrals are made. Nor are the effects related to managers behaving differently in treatment stores, as seen in a 
manager time use survey. Instead, our surveys suggest that effects are due to workers feeling respected because the ERP invited them to be involved in hiring, and because workers value having a say in who they work with. Arguably the most plausible alternative, that workers stay because they hope to make referrals in the future (i.e., an option value story), is much less supported.

Section 5 shows that ERPs are highly profitable, reducing labor costs by up to $2.8 \%$. About $5 \%$ of the savings reflects that referrals have higher retention than non-referrals (direct benefits), while $95 \%$ of profit gains come from ERPs boosting the retention of non-referred workers (indirect benefits). While direct benefits exceed the costs of an ERP, only comparing referrals vs. non-referrals dramatically underestimates the total benefits of an ERP.

Section 6 turns to heterogeneity analysis. Exploiting that our RCT was conducted across a large, national firm, we show that the overall impact of ERPs on attrition is larger in stores that were better performing before the RCT and in stores that are located in stronger local labor markets, as measured by the local unemployment rate. The profit benefit of ERPs is much larger in these stores. Overall effects are also larger among male workers compared to female workers.

Encouraged by the effects of the RCT, especially the indirect ones, the firm rolled out the ERP to all employees, including grocery workers in RCT control stores, as well as non-grocery jobs in logistics and food production, and also increased the referral bonus (Section 7). Once control grocery stores receive an ERP, attrition rates between treatment and control stores converge, consistent with long-run stability of ERP impacts. Referrals for grocery jobs increase from before, consistent with the increased bonus, but remain relatively modest. In contrast, for non-grocery jobs, the ratio of referrals to total hires is 3 times larger than for grocery jobs. Surveys with workers, managers, and the general public reveal that grocery jobs are seen as unattractive, and that workers who care for their friends may hesitate to refer friends for these jobs. Non-grocery jobs are seen as more attractive.

Our paper contributes to several literatures, most importantly, the one on management practices. Building on the robust empirical relation between management practices and outcomes, recent papers conduct RCTs on broad management practices (Bloom et al., 2013) or particular practices like work from home (Bloom et al., 2014). What is noteworthy in our paper is an RCT of a common management practice at-scale. ${ }^{4}$ To our knowledge, ours is the first, large-scale, within-the-firm RCT on any hiring procedure in any context. ${ }^{5}$ If only a

\footnotetext{
${ }^{4}$ Exceptions of at-scale, within-firm RCTs include Nagin et al. (2002), Blader et al. (2020), Gosnell et al. (2020), and Friebel et al. (2017, 2022), all on non-hiring topics.

${ }^{5}$ Development studies have randomized selection procedures in government (e.g., Ashraf et al., 2020) or NGOs (e.g., Del Carpio \& Guadalupe, 2022), but not in a private firm. Audit studies examine hiring issues across firms (instead of randomizing a firm's hiring procedures). Appendix A.2 discusses further.
} 
small subset of stores were treated, as in many within-firm RCTs, it would have been hard for us to observe the indirect benefits of ERPs. Our finding that the benefit of ERPs is larger in higher-performing grocery stores also exploits our RCT's large scale, and is consistent with ERPs being complementary to other HR practices, an idea discussed frequently in theory (Milgrom \& Roberts, 1990), but, beyond key exceptions like Ichniowski et al. (1997), Boning et al. (2007), and Blader et al. (2020), is often hard to examine empirically. ${ }^{6}$

Second, our results contribute to a small but influential literature on dual-purpose HR practices. As surveyed in Rebitzer \& Taylor (2011), HR practices can have multiple effects on workers, e.g., performance pay may both increase effort and attract better workers (Lazear, 2000). However, with some noteworthy exceptions (Ritter \& Taylor, 1994; Landers et al., 1996), evidence on dual-purpose HR practices is relatively scarce. We show that having an ERP generates referrals (who yield benefits to the firm relative to non-referrals) and separately causes workers to stay longer, arguably because they value being involved in hiring. Our results are consistent with the theoretical insight of Ellingsen \& Johannesson (2007, 2008) that workers care about being well-regarded by their employer. As far as we know, ours is the first academic paper in any field to show that ERPs can have broader organizational consequences beyond the referrer and referral.

Third, the paper substantially expands what is known empirically about referrals and especially about ERPs. Beyond how ERPs affect referral-making, our RCT enables us to assess how having an ERP and the level of referral bonus affect worker outcomes and firm profits. While larger bonuses increase referrals, we show for the first time that they decrease the quality of referral hires, illustrating a quantity-quality tradeoff. As surveyed by Topa $(2011,2019)$ and Hoffman $(2017)$, prior work on referrals from the perspective of firms compares average worker outcomes between referrals and non-referrals (e.g., Brown et al., 2016; Heath, 2018; Hensvik \& Skans, 2016), but lacks variation in ERPs (exogenous or otherwise) and thus cannot assess the firm consequences of ERPs - that is, our paper is the first to evaluate ERPs as a management practice. ${ }^{7}$ Building on Topa's (2019) suggestion for research to analyze how referral differences vary across local labor markets, we exploit the wide geographic scale of our RCT to show that ERPs have larger overall effects in better local labor markets. Last, our RCT provides evidence on what motivates referrers, which is useful given that referrals occur exogenously in most models of referrals. Ekinci (2016) is an

\footnotetext{
${ }^{6}$ We underscore that results are consistent with instead of indicative of complementarity, as we lack the detailed management surveys needed to measure non-ERP management practices.

${ }^{7}$ Papers randomize referral programs in non-inside-the-firm contexts to study different questions from ours, such as what type of customers should be targeted in customer referral programs (Kumar et al., 2010). In an RCT with survey enumerators for a research non-profit in Malawi, Beaman et al. (2018) study ERPs encouraging referrals of men, women, or people of either gender. Appendix A.2 discusses further.
} 
exception, providing a model of ERPs where potential referrers have career concerns.

\section{Conceptual Framework}

How might ERPs with different referral bonuses affect outcomes and why? Since ERPs may be a dual-purpose HR practice (Rebitzer \& Taylor, 2011), we discuss both in terms of direct effects (i.e., quantity and quality of referral hires) and overall effects. We then discuss how ERPs may affect firm profits, and how different effects may vary by store characteristics and job quality. To cover a range of different theories, our discussion here is verbal. Appendix $\mathrm{D}$ provides a model with analytic insights into many of these issues.

Starting with direct effects, one would imagine that larger bonuses would increase referrals, though this is not obvious. If larger bonuses signaled to workers that making a referral is difficult, the effect could be zero or even negative (Benabou \& Tirole, 2003). In terms of quality, one would expect following past work that referrals would be of higher quality than non-referrals. ${ }^{8}$ For example, if incumbent workers are altruistic toward their friends (Bandiera et al., 2009), they may only be willing to refer a friend if the match quality between the friend and the job is above a threshold. As the referral bonus increases, incumbent workers will lower their match quality thresholds, becoming willing to refer less qualified friends because the financial reward is higher. Thus, increasing the bonus should decrease the quality of referrals. The Appendix D model shows that this is the case.

We now consider the overall effects of an ERP, including indirect effects beyond generating referrals, such as possible effects on incumbent retention. Through an ERP, a firm is asking its workers to become involved in recruiting rather than carrying out this process only through HR and line managers. An ERP does not delegate formal recruiting rights, but it gives some real authority to the workers, as envisaged by Aghion \& Tirole (1997). Indeed, in our firm, 97\% of referred applicants during the RCT were hired, and surveys indicate that workers understood that their referrals would be hired. In other settings, like large high-tech firms in the US, it is often promised to employees that referrals will receive serious consideration instead of being lumped in the mass resume file (Bock, 2015). Workers are thus not only given the opportunity to work with their friends; the delegation decision may also be valuable in terms of what it communicates to incumbent workers.

As noted by Benabou \& Tirole (2003), decisions to delegate (e.g., by having an ERP) can communicate to workers that the firm believes workers to be of high ability and have

\footnotetext{
${ }^{8}$ This may occur because more precise signals are observed on referrals relative to non-referrals (Simon \& Warner, 1992; Dustmann et al., 2015); because good workers are friends with people like themselves (Montgomery, 1991; Hensvik \& Skans, 2016); or because referrer-referral ties reduce moral hazard (Castilla, 2005; Heath, 2018).
} 
good judgment. Workers may view such beliefs as a sign that the firm is likely to treat them well. Another possibility is that workers may intrinsically value the firm believing them to be altruistic. Ellingsen \& Johannesson (2008) present a model of respect in the workplace where a worker's respect is her second-order beliefs about her social preferences, i.e., her belief about the firm's beliefs about whether she is altruistic. Having an ERP may be a credible way for a firm to communicate its esteem, e.g., the firm may only be willing to have an ERP when it believes workers to be altruistic (either toward their friends or toward the firm), as such workers will be more concerned than selfish workers in avoiding bad matches. ${ }^{9}$ Provided that workers value feeling esteemed, having an ERP should increase retention, and Appendix D shows this formally in a signaling model. This prediction can be made even for stores where no referrals are made, since the signalling benefit occurs due to the firm having an ERP, not due to workers making referrals.

We suspect that involvement and delegation may be particularly beneficial when taking place within the realm of hiring. Anecdotally, while professors sometimes skip various faculty meetings, nearly everyone comes to faculty hiring meetings, suggesting that faculty like being involved in hiring. This is consistent with business case study evidence that involving workers in hiring can have broader organizational benefits (DeLong \& Vijayaraghavan, 2002).

It is not obvious that the signaling benefit of an ERP would be positive. Having an ERP could communicate that the firm is having a hard time recruiting through non-referral channels, or that it expects to experience significant turnover in the future, for which it would need to do a lot of hiring. Such sentiments could make workers more likely to quit.

Conditional on having an ERP, the signaling benefit of having a bonus or of using larger bonuses is also ambiguous. On one hand, using a bonus, and especially a larger one, exposes the firm to greater risk of opportunism, so it could be a sign of greater trust. On the other hand, using a bonus is not necessary to an altruistic worker who is strongly internalizing the interests of their friend.

Turning to profits, ERPs will increase profits if the overall benefits (direct and indirect) exceed the cost of referral programs. This is an empirical question. It also unclear how the bonus level will affect profits, either overall or in terms of direct effects. For example, higher bonuses may boost referrals, but also cost money and may decrease referral quality.

In terms of heterogeneity, ERPs should have larger impacts in stores where benefits of ERPs are reinforced. For example, that the firm respects its workers (a possible indirect benefit of ERPs) may be more credible when the store is functioning well. Also, workers may care more about respect in better labor markets, as their outside option may be better.

\footnotetext{
${ }^{9}$ This final point, that altruistic workers are more concerned in avoiding bad matches, may fail to hold if the people who benefit more from a job are ones who are less desirable for the firm.
} 


\section{Study Background}

The study firm. The firm is one of three main grocery chains in an Eastern European Union (EU) country. We avoid naming the country to protect confidentiality, as the firm is one of the largest in the country. Prior to the RCT, the firm's management changed. The new management decided to pursue a strategy of increasing quality, partly triggered by the threat of entry from Lidl, a discount German chain. Reducing turnover was declared a high-priority goal to assure quality service and decrease excessive worker training costs.

As is common for low-skill jobs in many countries, attrition is high, at an annual rate around $60 \%$ in stores during the pre-RCT period. ${ }^{10}$ Turnover costs are non-negligible, with direct (administrative and training) costs around $€ 250$ per exit, plus additional costs due to lost productivity (details in Appendix A.11). In meetings with the authors, executives expressed strong interest in reducing attrition, and this helped motivate our study.

The average store employs 25 workers. One is the store manager, 19 are general store workers, whom we refer to as cashiers, and the rest are department managers or specialists (e.g., butchers, bakers). Stores have average monthly sales of roughly $€ 200,000$. In its stores, the firm has roughly 4,500 cashiers, plus over 1,000 specialists and managers. The firm also has 1,200 workers in non-grocery-store jobs: logistics (primarily truckers), production (workers at a central food production facility), and a small number of white-collar jobs. Over our several years of personnel data, the number of employees observed is around 18,000.

Cashiers perform several functions, including stocking, cleaning, check-out, and answering customer questions. Most (95\%) work full-time, and receive an average monthly wage of roughly $€ 350$ (with minor variation depending mainly on if location is urban or rural), plus a bonus tied to store performance ( $4 \%$ of wages, on average). This performance bonus is quite small compared to the referral bonus. The cashier job has no formal requirements, so anyone's friend would presumably be qualified. Applicants are pre-screened via a centralized HR process. Those who pass the initial screen are sent to a store manager, who does interviews and makes hiring decisions. About $20 \%$ of non-referred applicants are hired. New cashiers receive two days of formal training (where they are paid but do not work), followed by two weeks of on-the-job training. Cashiers were $88 \%$ of grocery worker hires during the RCT. Specialists are paid about $€ 500$ per month on average, plus a bonus similar to cashiers.

Why the firm did the RCT. In October 2015, we met with the firm's top manage-

\footnotetext{
${ }^{10}$ As discussed below, turnover is particularly high for new hires: about half exit in the first 5 months. Such turnover rates are not atypical for low-skill jobs, e.g., about half of the call-center workers in Burks et al. (2015) exit within 90 days. We use "attrition" and "turnover" synonymously for worker exit.
} 
ment and suggested implementing an ERP via an RCT. ${ }^{11}$ Having an ERP was quite natural for the firm to consider for several reasons. First, the firm had an ERP during the 2000s, though it was discontinued in 2008 when the firm's growth came to a halt. Second, some of the firm's competitors pay referral bonuses. Third, we argued that an ERP could help reduce turnover. The firm was willing to do an RCT in order to investigate whether to have an ERP and in what form. ${ }^{12}$ While we helped in designing the RCT (including the randomization of stores into treatments) and monitored the RCT's implementation through our contacts in the central HR office, the RCT was carried out by the firm.

Referral process. According to the firm's definition, a referral occurs when someone is hired via the firm's formalized referral process. The process was designed so that making a referral would be as quick and easy as possible. To make a referral, an existing employee called a dedicated contact in HR and answered a few brief questions (name of referral, relation to employee, how long they have known them, how often they meet). The phone number and referral process details were listed in the poster put up in the staff common room in treatment stores (Figure 1), with variations depending on treatment arm. The referrer received a text message if the referral was hired, and could always call HR again for updates.

RCT details. We refer to the five RCT arms as Control; information only or "R0"; or information plus bonus, with the arms called R50, R90, or R120. In the Control arm, nothing changed relative to before the RCT. Workers were not informed about the possibility to refer. However, HR was told to accept referrals from Control stores if any were called in.

In the four treatment arms (R0, R50, R90, R120), store managers conducted information meetings with employees. During the meetings, all employees received a letter explaining the ERP, which store managers read aloud. Appendix E shows the letters. The meetings focused solely on the ERPs; managers did not tell workers that they were valued or that retention was important, nor did they discuss other worker concerns.

The central HR office ensured that meetings took place. Also, HR communicated with the regional managers (to whom store managers report) who monitored that store managers were in compliance with the new ERP. Neither workers nor store managers knew that an RCT was occurring. ${ }^{13}$ Beyond the information provided, workers in R50, R90, and R120

\footnotetext{
${ }^{11}$ Before running this paper's RCT, we worked with the firm on an RCT where (1) career incentives were emphasized to workers, or (2) the CEO communicated to store managers about the importance of reducing turnover (Friebel et al., 2022). Section 4.1 compares the impact of these treatments to our results. Controlling for a store's treatment status in Friebel et al. (2022) does not affect any of our results.

${ }^{12}$ The firm's executives are generally interested in running experiments (or "pilots"), particularly in regard to operations. Several pilots occurred during the ERP RCT (e.g., changing the order of items on the shelves).

${ }^{13}$ Regional managers were informed at a training event with one of the authors about the nature of the RCT. We felt it was important to inform regional managers about the RCT to ensure that stores were fully compliant. Regional managers were not involved in any operational or implementation aspects of the RCT,
} 
received $€ 15$ after the referral was hired to provide an immediate reward. The remainder of $€ 50$, $€ 90$, or $€ 120$ (i.e., an additional $€ 35, € 75$, €105) was paid if the referrer and referral stayed 5 months. This was clearly explained in the letter and posters, and workers hired after the RCT began were given letters explaining the ERP.

Rationale for bonus structure. We suggested a 5-month tenure threshold because a substantial share of cashiers leave in the first 5 months (about half in our pre-RCT data) while attrition is significantly lower after that. Tenure thresholds are very common in ERP bonuses (Brown et al., 2016; Burks et al., 2015; Fernandez et al., 2000; Fernandez \& Weinberg, 1997). To choose bonus amounts, we surveyed non-grocery workers, who were not part of the RCT. We asked them how much money would make them willing to make a referral for a hypothetical vacancy in their unit. We suggested bonus amounts for the treatment arms corresponding to the 25 th (€50 per referral), 50th (€90), and 75th (€120) percentiles of the distribution of survey responses. ${ }^{14}$ All bonuses were paid in after-tax amounts (i.e., the firm already paid the worker's taxable share), and relative to wages were substantial. The combined post-tax bonus of $€ 120$ represents $40 \%$ of a cashier's monthly post-tax salary, which is comparable to or higher than referral bonuses examined in other studies (Appendix A.3 gives details).

RCT timing. Materials (posters, letters, and instructions for store managers) were sent to treatment stores around $11 / 20 / 2015$, with instructions to implement the ERP immediately. Central HR and regional managers ensured compliance of treatment store managers with RCT procedures. We registered our RCT in the AEA Registry on 11/23/2015. In fall 2016, about a year after the RCT began, we met with top management to present the RCT results. After this, the firm decided to roll out an ERP to all firm jobs and to increase the referral bonus to $€ 30$ at hire and $€ 100$ after 3 months (see Section 7 for rollout details).

Safeguards to assure RCT validity. There are two immediate concerns for an RCT like ours. First, it is critical that employees in treated stores are aware of the ERPs. We address this using posters and letters to employees, and by having regional managers ensure that stores are in compliance. Also, in surveys carried out in fall 2016, $87 \%$ of employees in treatment stores reported being aware of the ERPs, indicating substantial awareness of the program, despite high employee turnover. Thus, there appears to be no compliance problem with the firm implementing the RCT.

Second, workers need to trust that bonuses will be paid. While trust is low in many post-Communist countries, we do not think this was a concern at all for us, given the group

but rather solely monitored whether store managers were complying.

${ }^{14}$ The non-grocery workers were told truthfully that we were surveying them as part of academic research; to avoid announcement effects, no explicit reference to any pilot project in the firm or to our RCT was given. 
meetings, and the paper trail from the company letters and posters. Workers were told that they could call HR about any questions on the ERPs. Further, given that the country is in the EU and has high formal legal standards, the firm is legally bound to pay bonuses it tells workers it will pay, and workers are aware of this. In the surveys we carried out (explained more later), we find no evidence of problems with procedural compliance in the RCT.

Data. We assemble the firm's personnel and accounting data for Feb 2014-May 2017 to create worker-month and store-month panels. The personnel data are for grocery store workers, cover over 18k workers (7k active only in the pre-RCT period, and $11 \mathrm{k}$ active during the RCT or beyond), and contain standard personnel variables (e.g., hire and termination dates, exit codes), as well as absences, earnings, bonuses, hours, and demographics. ${ }^{15}$ The personnel data also include information from the firm's ERP, including who the referrer and referral are, date of referral, and relationship of referrer to referral. ${ }^{16}$ We observe referred applicants (hired and not hired), though 85 of the 88 referred applicants during the RCT are hired, so referred hires and referred applicants are almost the same. Among non-referrals, we only observe hires, not applicants, though the firm informed us that roughly $20 \%$ of nonreferred applicants are hired. The main accounting variables are monthly sales, shrinkage (i.e., share of inventory lost to theft, spoilage, and other reasons), and operational profits (i.e., sales minus cost of goods minus wages minus shrinkage) by store.

Besides firm administrative data, we use surveys we carried out before, during, and after the RCT. In line with Ichniowski \& Shaw (2012), the surveys cover different types of respondents: store workers, store managers, and the country's general public. Topics include reactions to the ERPs; beliefs about mechanisms for the ERP effects; social perceptions of grocery jobs and our firm; and manager time use (Bandiera et al., 2020). Information on the surveys is discussed along the way, with details in Appendix A.4.

Randomization. The 238 stores were randomized into the five RCT arms. ${ }^{17}$ Table 1 shows that the five store groups are well-balanced over observables. In each row of columns 1-6, we regress a pre-RCT observable on a constant and dummies for the four treatment arms. Thus, the constant corresponds to the control group mean, and the coefficients correspond to differences between the different treatment groups and the control group. We also show

\footnotetext{
${ }^{15}$ The firm's non-grocery workers are not part of the RCT and are not in our worker-month panel. Thus, our analyses of non-grocery workers are more limited and use auxiliary data.

${ }^{16}$ In the firmwide rollout (Jan-May 2017), we only have data on who made referrals, not who was referred.

${ }^{17}$ Randomization took place on a coauthor's computer. Allocations were re-drawn numerous times until store averages were reasonably similar across the treatment groups in store employees ("head count"), attrition, sales, and store square footage. We control for these variables linearly in our regressions, as suggested by Scott et al. (2002) and Bruhn \& McKenzie (2009) for RCTs with multiply drawn randomization allocations. Our use of multiply drawn randomization allocations, coupled with significant correlations between many of the variables shown, contributes to the high p-values in Table 1, many of them close to 1.
} 
p-values for the F-statistic of joint significance of the four treatment dummies for each observable, and none are statistically significant. Columns 7-8 compare ERP stores (i.e., any of the treatments) vs. control stores, and we find no significant differences.

\section{Direct Effects: Quantity and Quality of Referrals}

\subsection{Impact of the ERPs on Generating Referrals}

Table 2 summarizes referral patterns across the five arms. There are 88 referred applicants and 85 referred hires. In 79 of 85 cases, referrals are hired in the same store as their referrers. Of the 6 exceptions, 3 are hired in Control stores, where no information about an ERP was provided and no referrals are made. There are also no referrals made in information only ("R0") stores. The number of referrals made monotonically increases with the bonus. Still, in the highest bonus arm ("R120"), only $5 \%$ of hires are referred.

Figure 2 plots the share of referrals made per hire over time, quarter by quarter, showing a modest ratio during the RCT. After the RCT, when a single ERP is rolled out to the entire firm with an increased bonus of $€ 130$ that is paid more quickly ( $€ 30$ instead of $€ 15$ at hire, and the remainder of the bonus after only 3 months instead of 5 months), referrals increase, with similar referral rates across the former RCT arms.

Using regressions, Table 3 shows RCT impacts of ERPs on whether a hire is referred:

$$
\text { Referred }_{i s}=\alpha+\sum_{k} \beta^{k} R_{s}^{k}+X_{i s} \delta+\epsilon_{i s}
$$

where Referred is $_{\text {is }}$ a dummy for whether worker $i$ in store $s$ was hired via referral, $R_{s}^{k}$ are dummies for the different store-level treatments (i.e., whether store $s$ has treatment $k$ ) where Control store is the excluded category, $\beta^{k}$ are the coefficients of interest, $X_{i s}$ are control, and $\epsilon_{i s}$ is an error. The controls are quarter-year of hire dummies, a dummy for being a cashier, demographic controls, and pre-RCT means of store-level characteristics (with the full list in the table notes). Standard errors are clustered by store, as ERPs are randomized by store. In addition, we perform randomization inference (Young, 2019), both for these results on direct effects and for our main results later on overall effects. The resulting p-values in square brackets are similar to those from conventional clustering-by-store inference. ${ }^{18}$

Column 1 of Table 3 regresses whether a hire is referred on dummies for the four treatment arms (an observation is a hire), showing that larger bonuses lead to more referrals. ${ }^{19}$

\footnotetext{
${ }^{18}$ Our findings are also unchanged under a wild bootstrap (Cameron et al., 2008). We cannot include store fixed effects in Table 3 because ERPs are randomized by store.

${ }^{19}$ The R0 coefficient is slightly negative, reflecting there are 3 referrals hired at Control stores and 0 at R0 stores. The 3 referrals hired at Control stores were referred by workers at different stores paying bonuses.
} 
The results are similar with controls in Column 2. Instead of using dummies for the four ERPs, Column 3 uses a dummy for having any of the four ERPs (the excluded category is again Control). Having an ERP increases the chance an employee is referred by 2.4pp. This is highly statistically significant, but seems economically modest.

Columns 4-6 of Table 3 analyze store-level referral hires during the RCT and yield similar conclusions. Having an ERP increases referral hires by 0.37 workers.

How does one square the low rate of referrals in our RCT with the understanding that a large share of jobs are typically found via networks? As noted by Topa (2019), a key distinction is between formal referrals through ERPs and informal referrals. As part of our During RCT survey in fall 2016, we surveyed 342 cashiers on how they found out about their jobs. For 154 workers hired during the RCT, 27\% said they found out about the job through a friend or family member working at the firm, within the $25-40 \%$ of hires through informal networks reported by Topa (2011) for Europe. Obtaining under $10 \%$ of hires through ERPs is also common in other firms. ${ }^{20}$ As noted by Topa (2019), the informal passing along of job information from person to person may differ qualitatively from deciding to formally refer someone to one's employer, with more important reputational considerations in the latter.

The 88 referrals occur in 34 stores and are made by 75 referrers. People tend to refer people like themselves demographically (Table B5), consistent with past work on referrals (Hoffman, 2017). Appendix A.5 provides additional facts on who makes referrals.

\subsection{The Quality of Referred Workers}

As described in the RCT pre-registration, our main outcome is attrition, and our secondary outcome is absence. We focus on attrition for three reasons. First, like many firms, our firm regards high attrition as a critical business issue, causing it to spend large sums recruiting and training new hires, and high-turnover stores also have lower sales. ${ }^{21}$ Attrition is the firm's primary HR key performance indicator (and its secondary one is absence). Second, worker retention is a standard measure of match quality (e.g., Dustmann et al., 2015). Third,

\footnotetext{
${ }^{20}$ Little is known about the share of workers getting hired through ERPs since survey data usually measure informal referrals. As of August 2019, of firms listed on ReferralPrograms.org, a site primarily focused on the US tech industry (where ERPs are common (Bock, 2015)), the mean share of hires through ERPs was 33\%, though a non-trivial share of firms (14\%) got 10\% or less of their hires from ERPs. For the four European firms on ReferralPrograms.org, the average share of hires from ERPs was $12 \%$, the same percentage as in grocery jobs at our firm in the post-RCT rollout (see Section 7). Also, talking to another large grocery chain in the country where our study firm is located, that firm's share of hires from ERPs was less than 5\% for grocery jobs. Thus, the fact that only a relatively modest share of grocery job hires at our firm comes from ERPs is consistent with data in other settings, particularly in the country we study and in Europe.

${ }^{21}$ Panel B of Table B7 shows the negative correlation between attrition and sales. High attrition also imposes serious costs in US retail firms (Ton, 2014). Kuhn \& Yu (2021) show that worker exits harm performance in Chinese retail stores.
} 
past work finds that some of the largest differences between referrals and non-referrals are in attrition (Hoffman, 2017; Topa, 2019), so it is natural to study attrition when analyzing ERPs. Absenteeism is also an important outcome in low-skill jobs and is costly for our firm, but we emphasize it less, first, because the firm regards attrition as the HR outcome of greatest interest, and second, because the distribution of days absent per month is highly skewed, yielding less precision in estimation. Another common outcome in supermarkets is a worker's items scanned per minute (Mas \& Moretti, 2009), but our firm does not regard it as a central performance variable, nor does the firm's IT system allow us to measure it. ${ }^{22}$

Attrition. Using workers hired during the RCT, Panel (a) of Figure 3 shows that referred hires have higher survival than non-referred hires.

To include control variables, in Table 4, we estimate Cox proportional hazard models: ${ }^{23}$

$$
\log \left(h_{i t}\right)=\alpha_{t}+\beta \cdot \text { Referred }_{i}+X_{i t} \delta
$$

where $h_{i t}$ is the attrition hazard of worker $i$ at month-of-tenure $t, \alpha_{t}$ is the log baseline hazard (i.e., tenure is controlled for nonparametrically), Referred $i$ is a dummy for being referred, and $X_{i t}$ are control variables. Beyond the controls from Table 3 (controls for quarter-year of hire, job type, demographics, and pre-RCT store means), we additionally include current month-year dummies, and all of these together will be our standard controls throughout the paper. $^{24}$ We use worker-months during the RCT. In column 1 of Table 4 , the coefficient of -0.59 implies that, compared to non-referred workers, referred workers are $45 \%$ less likely to leave each month, as $e^{-.59}-1=-0.45$. One explanation for this is better matching and a second is that the referral bonus encourages referrals to stay at least 5 months.

Column 2 analyzes referral differences in turnover separately during a worker's first 5 months of tenure and afterwards. In months 1-5, referral attrition is lower by $48 \%$ relative to non-referral attrition, whereas it is lower by $28 \%$ thereafter, though this latter difference is not statistically significant. ${ }^{25}$ Still, both differences are economically sizable, particularly in comparison to past work. ${ }^{26}$ While differences in attrition are strongest during the first 5

\footnotetext{
${ }^{22}$ Unlike in Mas \& Moretti (2009), in our firm, cashiers do a variety of tasks, so items scanned per minute is not conceptually synonymous with productivity. Still, not observing it is a limitation of our data.

${ }^{23}$ Our previous version of the paper used OLS to analyze attrition. Results are very similar with OLS.

${ }^{24}$ We include age in our analysis of direct effects of ERPs (i.e., in Tables 3-4) since age is only missing for a small share $(0.6 \%)$ of workers hired during the RCT. Later, in our analysis of overall effects of ERPs, we do not use age controls because age is missing for workers who are hired before the start of the data and who do not attrite ( $40 \%$ of RCT worker-months, $25 \%$ of workers), and mechanically, this missingness is highly correlated with attrition. Our main results are highly robust to different controls, including no controls.

${ }^{25}$ The post- 5 month referral attrition difference is statistically significant if we estimate a linear probability model (using the same tenure controls for attrition that we use for absence) instead of a Cox model.

${ }^{26}$ Burks et al. (2015) estimate that referrals are 10-11\% less likely to attrite than non-referrals for 8 firms with less skilled workers (i.e., call center and trucking firms). Thus, our referral attrition difference after 5 months is over twice as large as the overall referral difference in a large sample of broadly similar workers.
} 
months - consistent with the structure of the referral bonus - referrals may also be less likely to attrite after 5 months. Also, we do not see evidence that referrals are more likely to attrite after 5 months, which would be expected if referrals were staying longer than non-referrals solely to get a bonus. ${ }^{27}$ That referral differences are concentrated in the first 5 months does not mean that referrals are unuseful for the firm. Even if referrals stayed longer solely to get a bonus, which seems unlikely based on our results and prior evidence for matching and positive selection (Brown et al., 2016; Dustmann et al., 2015; Pallais \& Sands, 2016; Simon \& Warner, 1992), this could still be valuable to the firm, as it strongly wants to cut turnover.

Consistent with the quantity-quality tradeoff in our conceptual framework, column 3 of Table 4 shows that referral attrition differences are smaller at higher referral bonuses. For the R50 group, the referral attrition difference is $85 \%$. In contrast, for the R90 and R120 groups, the referral differences are $40 \%$ and $35 \%$, respectively. These differences are statistically significant ( $p=0.02$ for R50 vs. R90; $p=0.01$ for R50 vs. R120).

Table 4 classifies referrals according to the store where they work. However, results are robust to excluding the 6 referrals who get hired in different stores than their referrers. The results are also robust to excluding referrers from the sample.

Absences. As the distribution of monthly absences is highly skewed, we analyze worker $i$ 's monthly absences, Absences ${ }_{i t}$, using negative binomial models of the below form:

$$
\text { Absences }_{i t}=G\left(f(t)+\beta \cdot \text { Referred }_{i}+X_{i t} \delta\right)
$$

where $G(\cdot)$ is the negative binomial function and $f(t)$ are controls for tenure. As in most European countries, it is easier to fire workers during a probationary period, and absences are thus more costly to the worker and less common (see Figure B2) during probation (Ichino \& Riphahn, 2005). Probation at our firm lasts 3 months, as is typical for the country we study. Thus, we control for a probation period dummy, plus linear terms in tenure on both sides of 3 months, and these will be our non-Cox tenure controls throughout the paper.

Column 4 of Table 4 implies that referrals have 19\% fewer absences per month (based on exponentiating the coefficient), but this is not statistically significant. Column 5 shows that, during the first 5 months, referrals have $36 \%$ fewer absences than non-referrals, which is sizable and marginally statistically significant, but after that, there is no evidence for a difference. This could be due to referrals not wanting to be fired before 5 months to ensure their friend gets a bonus. Referral differences do not significantly vary by bonus size.

Adding store dummies. For analyzing referral/non-referral differences, we can add store fixed effects, which is useful given it is a non-randomized comparison. ${ }^{28}$ Appendix

\footnotetext{
${ }^{27}$ Appendix Figure B1 shows that referrals have lower attrition at most months of tenure.

${ }^{28}$ In our main results on the overall impact of ERPs, we cannot control for store fixed effects because ERPs are randomized at the store level, though we can control for store fixed effects if we exploit pre-RCT data.
} 
Table B2 shows that referral attrition differences are similar (and slightly larger) when store fixed effects are added. Absence differences are statistically insignificant and noisy. Broadly consistent with Burks et al. (2015), there are stark referral differences in attrition, but we do not observe significant differences in our non-attrition performance variable of absence.

\section{The Overall Impact of ERPs on Worker Outcomes}

\subsection{Results}

Attrition. Table 5 shows that ERPs reduce attrition of all workers, with substantial effects on both new hires and incumbents. Beyond showing robustness to randomization inference, that ERPs reduce attrition is also robust to accounting for a multiple hypothesis testing concern, namely, that we have two key outcome variables (see Appendix A.6 for details).

Column 1 of Table 5 shows the impact of the randomized ERP treatments on attrition during the RCT (as opposed to comparing referrals vs. non-referrals) using Cox models:

$$
\log \left(h_{i s t}\right)=\alpha_{t}+\sum_{k} \beta^{k} R_{s}^{k}+X_{i s t} \delta
$$

where $h_{i s t}$ is the attrition hazard of worker $i$ at store $s$ at month-of-tenure $t$. As in equation (1), $R_{s}^{k}$ are dummies for the store-level treatments. Relative to workers in Control stores, workers in R0, R50, R90, and R120 stores have monthly attrition that is lower by roughly 15\%,7\%, 25\%, and $13 \%{ }^{29}$ These differences are statistically significant for R0, R90, and R120. Column 2 shows that having an ERP reduces attrition by about $15 \%$. Given that referrals are only $2.5 \%$ of hires in ERP stores, it seems unlikely that these differences are primarily due to referrals staying longer than non-referrals or people becoming more likely to stay as a result of making a referral. Comparing R0 vs. Control, recall there are 0 referrals made and 0 referral hires in $\mathrm{R} 0$ stores. Thus, any reduction in attrition in $\mathrm{R} 0$ stores relative to Control stores cannot be due to workers being referred or making referrals.

Though our treatments are randomized, we may obtain additional power or control by exploiting the personnel data before the RCT. Columns 3-4 of Table 5 report the results from a "diff-in-diff" Cox model where treatment arms are interacted with a dummy for whether the current month is during the RCT:

$$
\log \left(h_{i s t \tau}\right)=\alpha_{t}+\gamma_{s}+\sum_{k} \beta^{k} R_{s}^{k} \cdot 1(\tau \text { in } \mathrm{RCT})+X_{i s t \tau} \delta
$$

where $\tau$ indexes the current month-year and 1( $\tau$ in RCT) is a dummy for $\tau$ being during the

\footnotetext{
${ }^{29}$ For ease of exposition, as is common for Cox models (e.g., Chetty, 2008), we interpret the overall ERP treatment effect coefficients in log points as rough percentage effects. The approximation is close for overall effects, whereas we avoided doing this for Table 4, where the approximation is less valid.
} 
RCT. Store dummies, $\gamma_{s}$, account for persistent differences across stores in employee attrition and other characteristics (including treatment arm during the RCT). Relative to column 1, results are slightly stronger in column 3 , with statistical significance for all 4 ERPs. The column 4 coefficient of -0.20 corresponds to a reduction of roughly $20 \%$.

To better understand the dynamics of the ERP effects, Figure 4 presents an event study where having an ERP is interacted with quarterly dummies for time relative to the start of the RCT. Since standard event studies are based on linear models (Borusyak et al., 2021), we momentarily turn away from Cox, and we estimate linear probability models:

$$
y_{i s t \tau}=f(t)+\gamma_{s}+\sum_{q} \beta^{q} E R P_{s} \cdot 1(\tau \text { is q quarters from start of RCT })+X_{i s t \tau} \delta+\epsilon_{i s t}(6)
$$

where $y_{\text {ist } \tau}$ is a dummy for whether worker $i$ at store $s$ with tenure $t$ attrites at time $\tau, f(t)$ are controls for tenure (same as in equation $(3)$ ), $\beta^{q}$ are the coefficients of interest, $E R P_{s}$ is a dummy for whether store $s$ has an ERP, and $\epsilon_{i s t \tau}$ is an error.

Panel (a) of Figure 4 shows overall results. While ERP effects seem to take a few months to realize, with the largest estimated impact in the RCT's 2nd quarter (Mar. 2016May 2016), we cannot statistically reject that effects are the same throughout the RCT. The magnitudes of ERP effects (i.e., a drop of 1pp below the base of $6 \mathrm{pp}$ ) remain economically important over the 13 months of the RCT, with an ERP impact of $-15 \%$ in the RCT's final quarter. After the RCT ends, and an ERP is rolled out to Control stores, the attrition difference between treatment and Control stores vanishes.

Figure 4 immediately suggests that the ERP impact on attrition is not driven by referrals. Specifically, panel (b) of Figure 4 shows similar results to panel (a) while restricting to stores where no referrals are made during the RCT. Instead of showing the difference between Control and ERP stores, panel (c) of Figure 4 shows separate regressions restricting to Control or ERP stores. Attrition is higher during summer, as for many retail jobs, and increases over time as the country's overall economy improves. Repeating panel (c) but restricting to stores with no RCT referrals, panel (d) shows similar results, thereby reinforcing the message of the comparison between panels (a) and (b).

The impact of ERPs on attrition is driven by a decrease in voluntary attrition ("quits"), as seen in Figure B3, which plots event studies separately by quits and "fires" (involuntary attrition). ERPs have no significant impact on fires. Relative to Figure 4, precision is even stronger when focusing on quits, which is unsurprising if ERPs only affect quits.

Returning to Cox models in Table 5, columns 5-8 show that attrition impacts are sizable among both new hires and incumbents, i.e., people already working at the firm at the start of the RCT. Using equation (4), we estimate that ERPs reduce new hire attrition by $11 \%$ (column 6 ) and incumbent attrition by $19 \%$ (column 8 ). That ERPs reduce incumbent 
attrition is important for thinking about mechanisms, as discussed below in Section 4.2.

Attrition magnitudes. Having an ERP reduces attrition by 15-20\% durably for 13 months. As a benchmark, Friebel et al. (2022) study two treatments in an earlier RCT with the study firm. First, informing workers about career incentives (i.e., that managers are promoted from within) had no impact on turnover. Second, a letter from the CEO to store managers asking them "to do what they can" to reduce turnover led them to spend more time with employees and brought down turnover by about $25 \%$ for several months before reverting back. The firm has also tried out various initiatives on their own to reduce turnover and most have been unsuccessful.

The RCT ERP is one of the most successful initiatives the firm has ever had in terms of reducing turnover. This is noteworthy, as the firm is mature and modern, and has had top executives with prior experience leading major grocery chains in Western Europe.

Besides being economically sizable, the magnitude of ERP effects is plausible. As another benchmark, Bloom et al. (2014) show that randomly assigning workers to work from home reduces attrition by half in Chinese call centers. Cai \& Wang (2022) show that allowing workers to evaluate their managers reduces attrition by over half in a Chinese car factory. Adhvaryu et al. (2022) show that assigning workers to participate in an anonymous survey about working conditions leads to a $20 \%$ drop in turnover in an Indian garment factory.

Bonus size and attrition impacts. On visual inspection, Table 5 shows no clear relation between the size of the referral bonus and the treatment effect on attrition. For example, consider incumbents (results in column 7), who are a key group to consider since ERPs cannot affect their selection into the firm. The largest treatment effect is from R90, where $€ 90$ are paid, but the second largest effect is from R0, where no bonus is paid. ${ }^{30}$

To analyze this more systematically, in panel (a) of Figure 5, we take models from Table 5 and add interactions of ERP with the inverse hyperbolic sine of bonus size:

$$
\log \left(h_{i s t}\right)=\alpha_{t}+\beta_{0} E R P_{s}+\beta_{1} E R P_{s} \times \operatorname{asinh}(\text { Referral Bonus Size } s)+X_{i s t} \delta
$$

Figure 5 presents the key interaction coefficients, $\beta_{1}$. We present results for all workers and incumbents. Besides using all stores, to isolate indirect effects, we also show results restricted to stores with no referrals made in the RCT. The interaction is statistically insignificant in all 4 cases and the "zeros" are reasonably precise. The 95\% confidence intervals are between -0.024 and 0.041 , meaning that increasing the inverse hyperbolic sine of bonus size by one point (i.e., roughly doubling) would not decrease the ERP treatment effect (i.e., increase it in magnitude) by more than 0.024 log points, and would not increase it by more than 0.041

\footnotetext{
${ }^{30} \mathrm{~A}$ joint F-test can marginally reject that all four treatments are equal $(p=0.075)$. However, if one restricts to stores with no RCT referrals, in an effort to isolate indirect effects, we fail to reject that the treatment effect is uniform across the treatments for incumbents $(p=0.19)$.
} 
log points. Thus, with $95 \%$ confidence, we can rule out that increasing asinh(bonus size) by one point would take an ERP effect of $15 \%$ and turn it to more than $18 \%$ in magnitude.

Panel (b) of Figure 5 shows that there is no significant difference in having an ERP with no bonus vs. having an ERP with any bonus. We estimate models similar to the odd columns of Table 5 except that we lump R50, R90, and R120 together to create a dummy for having any bonus. Across the four specifications, we never reject that the attrition impact of an ERP with a bonus is different from the attrition impact of an ERP with no bonus.

Absences. Table B3 shows no significant impact of ERPs on absence. We see no effect for having an ERP overall or for the individual ERPs. Why do ERPs have no significant effect on absence despite reducing turnover? First, since the distribution of absences per month is highly skewed, this yields less precision in estimation. Based on the $95 \%$ confidence intervals in Table B3, we rule out that ERPs cause large reductions in absence, but we cannot rule out moderate ones, e.g., in column 2, we cannot rule out that ERPs reduce absence by less than $12 \%$. Second, it could be that turnover is easier to affect in general than absence. Third, the feeling of respect and voice generated by ERPs (discussed in detail below) could lend itself to reducing turnover more than absence. It is hard to separate these possibilities. Finding effects on turnover but not absence is sometimes found in other management interventions (Cai \& Wang, 2022), and is consistent with our preferred mechanism discussed below.

Total hires and other store-level outcomes. Table B4 presents impacts of having an ERP on store-level outcomes using a store-month panel. Panel A uses only data from the RCT, whereas Panel B exploits the pre-RCT period to add store fixed effects, as in columns 3-4 of Table 5. As seen in column 1 of Table B4, total store hires decline by 0.13-0.22 hires per month. This decrease of 10-19\% in hires is consistent with our 15-20\% drop in turnover. The impact is statistically significant at the $10 \%$ level in Panel B, but not in Panel A.

Table B4 also shows that ERPs do not have a statistically significant effect on stores' monthly shrinkage, sales per worker, operational profit per worker, or total hours worked. Still, the coefficients on hires, shrinkage, sales, and operational profit have a sign indicating benefit to the firm, and the magnitudes are economically sizable despite being noisily estimated. ERPs are estimated to increase operational profits by $2.0-2.3 \%$; increase sales per worker by $2 \%$; and cut shrinkage by $1.7-2.5 \%$. For these additional outcomes that we did not pre-register as main outcomes, we lack power to detect small to moderate changes using only store-month data. ${ }^{31}$ We see no evidence that ERPs harm store-level outcomes.

\footnotetext{
${ }^{31}$ Thus, in analyzing impacts on profits in Section 5, we combine the treatment effects on attrition with two values of the cost of turnover, with one intended to account for lost sales following Blatter et al. (2012).
} 


\subsection{Mechanisms for Overall ERP Impacts}

The simplest reason an ERP would cut turnover is by promoting referrals, as referrals are less likely to quit and referrers may be more likely to stay to get a bonus. However, Section 4.2.1 provides evidence that promoting referrals explains only a modest share of ERP impacts. Section 4.2.2 discusses additional mechanisms that, while plausible ex ante, are ex post inconsistent with the main RCT results (i.e., relatively few referrals, but sizable ERP effects on attrition) and basic institutional facts. Section 4.2.3 discusses mechanisms that are consistent with the main RCT results, including our preferred mechanism of workers valuing being involved in hiring, and uses surveys and additional data patterns to tease these apart.

\subsubsection{Assessing Referrals as a Mechanism}

How much of the effect of ERPs on attrition (a 15\% reduction) comes via effects related to referrals, i.e., getting more referrals or making referrers more likely to stay? The simplest evidence against referrals as the main mechanism comes by comparing $\mathrm{R} 0$ and Control stores. Workers in R0 stores have roughly $15 \%$ lower attrition than workers in Control stores, even though the R0 treatment induced no referrals.

Second, our main attrition results are similar when restricting attention to stores where no referrals are made during the RCT. Beyond the event studies in Figure 4, this is also seen in Cox models in Table B6, which repeats Table 5 restricted to stores with no RCT referrals made. If no referrals are made in a store, then there are no referrers, and only referrals that are made from other stores, making it very hard for referrals to drive the impact of ERPs. ${ }^{32}$

A final way to address this question is mediation analysis, with details in Appendix A.7. We repeat the analyses in columns 1-2 of Table 5, but additionally control for whether someone is referred and/or the number of referrals a person has made to date. The estimates imply that only $5 \%$ of the impact of having an ERP on attrition is mediated via having more referral hires and having workers made more referrals to date. Also, relative to someone who has not made a referral, someone who has made a referral is no more likely to stay on average, though they are more likely to stay in the first 5 months after a referral.

\subsubsection{Unlikely Mechanisms for Non-referral Channel}

Peer effects in attrition from referrals. It is unlikely that peer effects from referrals or referrers drive our results. First, there were relatively few referrals made. Second, and more

\footnotetext{
${ }^{32}$ Results are similar if we restrict to stores with no referral hires (instead of no referrals made). Panels (c) and (d) of Figure 3 show that non-referrals have better survival in ERP than Control stores.
} 
importantly, the overall impact of having an ERP on attrition is similar to our baseline estimate even while restricting to stores where no referrals are ever made during the RCT.

ERPs help the firm improve hiring decisions. Perhaps ERPs help store managers learn about what type of candidates to hire, or free up time spent on interviews? This is also unlikely to explain our results. Beyond the fact that ERPs have large effects in stores where no referrals are made, ERPs have sizable impacts on incumbents (in addition to affecting new hires). This mechanism cannot explain why ERPs reduce incumbent attrition.

Concurrent policies or managerial reactions in treatment stores. Throughout the RCT, the firm did not differentiate any non-ERP management practice by treatment status. Recall that store managers were not aware there was an RCT. Further, having an ERP did not affect firing or self-reported store manager time use. Time use details are in Appendix A.8.

Control store frustration. Instead of workers in treatment stores being less likely to quit, perhaps workers in control stores became more likely to quit, if they happened to hear about the ERPs in other stores. There is evidence against this interpretation. First, HR was told to accept referrals from control stores if employees called to make them, but they did not get any referrals from control stores. Second, we instructed HR to record any complaints that it received from control stores about there not being an ERP, but there were no complaints made. Third, in all the surveys we conducted, both during and after the $\mathrm{RCT}$, we never heard a worker mention anything about control store frustration.

\subsubsection{Possible Mechanisms for Non-referral Channel}

The impact of an ERP is strong in stores where no referrals are made; is relatively flat over time; does not systematically vary with bonus size; is substantial for hires and incumbents; is driven by quits, not fires; and treatment/control differences vanish once the ERP is rolled out to control stores. What explains this? It should be a mechanism or mechanisms that increase the non-wage value of working at the firm. Such mechanisms may include:

1. Employees feel respected after being asked to be involved in hiring or liked having some say about who they might work with. Workers may value being involved in hiring, perhaps because it makes them feel respected (Ellingsen \& Johannesson, 2007; Sockin, 2021; Dube et al., 2021), or because it gives workers some voice (Hirschman, 1970; Turco, 2016) or real authority (Bartling et al., 2014; Rasul \& Rogger, 2018) in hiring.

2. The introduction of an ERP is a positive signal about the firm being a better place to work. Instead of being simply about hiring or whom a worker gets to work with, an ERP may increase a worker's perception of the overall quality of the firm, e.g., having a costly ERP may raise a worker's expectation of the firm's future profitability. 
3. Workers think they may make referrals in the future. Even if relatively few workers made referrals during the RCT, workers may think that they will do so in the future.

4. ERPs increase informal referrals. The ERPs could have increased informal referrals, i.e., people who may have informally heard about the job from a friend, but where the friend may not have been willing to call HR to register the referral.

Before turning to surveys, note that the "option value" story of (3) implies that ERP impacts on turnover should increase with referral bonus size: if workers stay because they hope to make a referral in the future, then workers should be more likely to stay when the bonus is higher. In contrast, signaling mechanisms do not predict a clear, positive relation between bonus size and treatment effects. Figure 5, discussed above, shows no such relation.

To shed further light on these explanations, we conducted surveys with store managers and workers from the study firm. Specifically, we did phone surveys with 222 store managers (or 93\% of store managers) and an in-store electronic kiosk survey with 113 grocery store cashiers. These cashiers are broadly representative of cashiers at the firm. ${ }^{33}$ We explained that ERPs had reduced attrition at the firm separate from generating referrals, and asked them their opinion on which of the above four mechanisms (or a 5th option of a mechanism of their own choosing) was most likely to explain the result. We randomized the order in which the above four mechanisms were presented, with the option for the respondent to provide their own alternative mechanism always presented last, as is common in surveys.

Panel A of Table 6 shows that mechanism (1) is by far the most commonly chosen explanation, chosen by $66 \%$ of managers and $50 \%$ of workers. There are modest differences between workers and managers, e.g., a larger share of workers believe in mechanism (3), but the overall message from both groups is the same.

Is it possible to parse further into whether (a) employees felt respected about being involved in hiring or (b) whether they liked having some say about who they might work with? We asked workers to specify whether (a) or (b) was more likely to be the mechanism or whether both were equally likely. As seen in Panel B of Table 6, 15\% said (a), 18\% said (b), and $67 \%$ said both were equally likely. While (a) and (b) may be conceptually distinct, workers view them as closely related. ${ }^{34}$ We refer to (a) and (b) together as workers valuing being involved in hiring. While researchers have not previously considered that

\footnotetext{
${ }^{33}$ The 113 cashiers represent only about $2 \%$ of cashiers at the firm, reflecting that only a small number of workers were asked to participate in the survey. However, as seen in Appendix Table B1, the characteristics of store workers who participate in our survey are similar to the overall population of grocery store cashiers. Based on our discussion with the firm, we believe that the firm asked workers to participate essentially at random, and this understanding is supported by the evidence in Table B1.

${ }^{34}$ This is unsurprising. Part of why someone may feel respected is that the firm is allowing them to help influence who they might work with. Our results on (a) vs. (b) are similar when restricting to respondents choosing mechanism (1) as the most likely explanation.
} 
workers valuing being involved in hiring is a mechanism for the impact of ERPs, it is highly consistent with evidence from practitioners, as we discuss further in Appendix A.9.

For ERPs to credibly signal respect in mechanism (1), workers must believe that candidates they refer will be hired. Indeed, $97 \%$ of referred candidates were hired compared to roughly $20 \%$ of non-referred candidates. Furthermore, this very high likelihood for referrals to get hired was well-understood by workers. In our phone survey of managers, in a random subset of roughly half the managers, we asked managers on how workers thought that referred candidates would be treated. Most indicated that workers believed that referred candidates would likely be hired, giving a mean of 6.1 on a scale between 1 (don't believe a referred friend would be hired) to 7 (are sure a referred friend will be hired), with $N=102$ managers. In our in-store kiosk survey of 113 workers, we asked the same question to workers, and received a quite similar mean of 5.8 out of 7 .

Beyond surveying firm managers and workers about reasons for the indirect effects, a complementary approach to identifying mechanisms is to use a vignette. In late 2018, we surveyed a representative sample of 548 US workers, what we call the Vignette Survey of US Workers. This allows us to study whether the mechanism we identify may hold in other contexts. We used the following vignette (with bolding as in the original):

An employee is working at a firm where an employee referral program is introduced. Under the program, employees are asked to refer their friends for jobs, and they are paid a bonus if their friend is hired. In addition, under the referral program, the firm will provide special consideration in the hiring process to referred candidates. Do you think the firm having the employee referral program would make the employee feel more respected?

In the survey, $68 \%$ of workers said having an ERP would likely make the employee feel more respected, whereas only $11 \%$ said it was unlikely to make the employee feel more respected, and $21 \%$ said they were uncertain. Appendix A.10 provides details on the Vignette Survey.

Overall, our evidence indicates that most of the impact of ERPs does not come from generating referrals. Rather, the explanation most supported by the survey evidence (intrafirm and US vignette) and intra-firm data patterns is that workers feel respected after being asked to be involved in hiring or value having some say about who they might work with.

\section{The Impact of ERPs on Firm Profits}

We use the results from Sections 3-4 to calculate the profitability of the ERPs. Past work calculates the profits of hiring a referral relative to a non-referral (Fernandez et al., 2000; 
Burks et al., 2015), but has yet to be able to calculate profit gains from an ERP. Since the ERPs reduced turnover, but did not significantly affect absence, sales, or shrinkage, we focus only on attrition impacts. ERPs may also reduce recruiting costs (e.g., due to less time interviewing candidates), but we set that aside, given we lack applicant data on non-referrals.

The attrition benefit of an ERP per worker-month is $t c$, where $t$ is the ERP's impact on turnover in terms of worker exits avoided and $c$ is the turnover cost. Since Cox gives effects in percent terms instead of absolute levels, we estimate $t$ using an OLS version of column 2 of Table 5 (see column 3 of Table A3). We present results where $c$ is based on direct, administrative costs $(c=€ 250)$ or where $c$ is based on the "full costs" of higher turnover $(c=€ 1,150)$. Direct costs account for job advertising costs and the time spent by employees to hire someone. Full costs additionally account for lost productivity costs, which are hard to precisely detect experimentally, but which we account for following Blatter et al. (2012).

We also calculate benefits separately for referrals, non-referral new hires, and pre-RCT incumbents. For population $p$, the benefit of lower turnover is $\theta_{p} t_{p} c$, where $\theta_{p}$ is the share of ERP store worker-weeks represented by $p$, and $t_{p}$ is the attrition difference within $p$. See Appendix A.11 for details on $c$ and Appendix A.12 for details on calculating profits.

The cost of an ERP is the bonus paid to the referrer. The pre-tax cost per referral is $b_{0}+\operatorname{Pr}($ both $) * b_{1}$, where $b_{0}$ is the bonus paid upon hire; $\operatorname{Pr}($ both $)$ is the probability that referrer and referral stay 5 months after the referral; and $b_{1}$ is the bonus paid after 5 months.

Profit results. Panel A of Table 7 reports the overall benefits from having an ERP vs. not. Starting with $c=€ 250$, the benefit from an ERP is $€ 2.49$ per worker-month, far above the cost per worker-month of $€ 0.10$. Overall net profit per worker-month is $€ 2.39$ or $0.6 \%$ of labor costs. Only $5 \%$ of the turnover benefits come from ERPs yielding referrals, who have lower attrition. Most of the benefit comes from incumbents and non-referral hires having lower attrition in ERP stores. Under $c=€ 1,150$, ERPs become even more profitable, increasing profits by $€ 11$ per month, or $2.8 \%$ of labor costs, a substantial benefit in a competitive industry like grocery retail.

If ERPs are evaluated solely based on lower turnover from referrals (i.e., direct benefits alone), benefits outweigh costs, with a return on investment (ROI) of $30 \%$ for $c=€ 250$ and an ROI of $498 \%$ for $c=€ 1,150$, where ROI $=100^{*}$ (Benefit-Cost)/Cost. However, the comparison is vastly different once we account for ERPs' indirect effects on turnover. Accounting for direct and indirect effects, the ratio of ERP benefits to costs goes up by a factor of 20 .

Panel B of Table 7 repeats Panel A separately for the different ERPs. We use the more conservative $c=€ 250$. Direct benefits (i.e., turnover benefits from referrals hired during the $\mathrm{RCT}$ ) are non-monotonic in the bonus, reflecting differences in the quality and prevalence of referrals across treatment arms. Overall turnover savings are also non-monotonic in the 
bonus, reflecting the non-monotonic relation in column 1 of Table 5. Focusing only on direct benefits yields misleading conclusions, e.g., on direct benefits alone, there is little profit benefit from R120. R0 yields large overall gains despite producing 0 referrals.

Panel C looks at profits under the post-RCT firmwide ERP rollout (discussed in further detail in Section 7). The share of turnover benefits from referral hires is $13 \%$, which is higher than during the RCT, but most benefits are still not from referral hires.

TFP. Given the decrease in labor costs of 0.6\%-2.8\%, plus an assumed output elasticity of labor for retail of 0.7 (Shin \& Eksioglu, 2015), as well as our imprecisely-estimated increase in sales of $2 \%$, our results imply an increase in TFP of roughly $2-4 \%$. This effect is comparable to that in Englmaier et al. (2017), who find a TFP increase of $4 \%$ from better communication of an incentive system, and Friebel et al. (2017), who find a productivity increase of $3 \%$ from team incentives, both estimated in Europe. It is smaller than the effect of working from home (Bloom et al., 2014) and extensive management consulting (Bloom et al., 2013) using RCTs in China and India, which is unsurprising given that those are more extensive interventions.

\section{Heterogeneity in ERP Impacts on Attrition}

While we focus on the pre-registered overall impact of ERPs on attrition, we here examine heterogeneity based on two dimensions often discussed in the management practices literature, as well as by gender and job type. ERP impacts are larger in higher-performing stores, in better local labor markets, and among male workers.

Store performance. A key question in experimentally evaluating any management practice is how do effects vary based on initial performance of the treated units? To measure pre-RCT store performance, we create a performance index from three standard variables of retail performance: shrinkage rate, $\log$ (Sales per Worker), and Log(Operational Profits per Worker). To create the index, we normalize these variables, take the mean of the three, and then normalize again to ease interpretation. ${ }^{35}$ As seen in column 1 of Panel A of Table 8, the direct effect of ERPs on referrals does not significantly vary with store performance.

However, the overall effect of ERPs on attrition is significantly larger in stores with higher performance pre-RCT. As seen in column 1 of Panel B of Table 8, for a store at the mean level of store performance, the impact of having an ERP on attrition is about

\footnotetext{
${ }^{35}$ Our approach to index creation follows past work such as Deming (2017). Panel B of Table B7 shows the correlation between the variables in the index, whereas Panel A shows the correlation of our main heterogeneity variables, including the index. To assess how direct benefits of ERPs vary by store performance, one also needs to know how referral differences vary. Table B8 shows that referral attrition differences may be larger in higher-performing stores, but the heterogeneity relationship is not statistically significant.
} 
$13 \%$. However, for a store at the 90th percentile of performance, the ERP impact is $27 \%$, whereas for a store at p10, the impact is essentially zero. This result is robust. Table B9 shows a similar finding while splitting the sample based on above/below median pre-RCT performance, thus showing that our heterogeneity conclusion is not driven by outliers or our use of linear interaction terms. Our findings are also robust to analyzing the three performance variables individually instead of using an index (Table B10). In contrast, ERP impacts do not vary based on stores' pre-RCT attrition rates.

An interpretation of these results is that the ability of ERPs to generate feelings of involvement and respect is higher in higher-performing stores. In lower-performing stores, the notion that the firm respects its workers may be less credible. The results are also consistent with complementarity between ERPs and the other management practices that drive performance in those stores. ${ }^{36}$ Thus, our results are broadly consistent with work showing HR practice complementarity (Ichniowski et al., 1997; Boning et al., 2007), as well as supportive of theories of management practice complementarity.

Local labor markets. Another key question in analyzing an HR practice is how do effects vary by labor market quality? This is hard to answer in most RCTs because it requires observing effects across many labor markets. Beyond work on management practices, as noted by Topa (2019), examining heterogeneity in referral results by strength of the local labor market is important because theories predict that referrals do different things in tight and slack labor markets (Calvo-Armengol \& Jackson, 2004). We exploit substantial crossmunicipality variation in 2015 unemployment rates: across the 238 stores, which are in 78 municipalities, mean unemployment is 7.7 , the $\mathrm{SD}$ is 2.3 , the $\min$ is 4.8 , and the max is 15.4 . A municipality approximates a worker's local labor market in the country we study.

The direct effect of ERPs does not vary by labor market quality (column 3 of Panel A of Table 8). However, Panel B shows that the overall effect of an ERP on attrition is significantly larger in better local labor markets. If the municipal unemployment rate is at p90 (i.e., the local labor market is bad), our results imply that the impact of ERPs on attrition is roughly $-2 \%$. In contrast, if the unemployment rate is at p10, the ERP impact on attrition is $-28 \%$. In tight labor markets, workers have more options, so attrition may respond more strongly to $\mathrm{HR}$ practices that make workers feel more respected. Our results are broadly consistent with Burks et al. (2015), who show that differences between referrals and non-referrals tend to be larger in stronger local labor markets. The difference is we study the impact of ERPs, which are primarily driven by indirect effects, whereas Burks

\footnotetext{
${ }^{36}$ Results are consistent with instead of indicative of complementarity because we do not measure whatever practices may drive cross-store performance differences. Non-management explanations are possible but seem unlikely (e.g., product selection and technology are similar across stores). Appendix A.13 discusses further.
} 
et al. (2015) examine referrals vs. non-referrals. ${ }^{37}$

Heterogeneity in ERP impacts by worker characteristics. Columns 4 and 5 of Table 8 examine heterogeneity in ERP impacts by two key worker characteristics: gender and job type, namely, whether a worker is a cashier. Recall that cashiers are the entry-level generalists in the grocery stores, and the alternative is being a specialist (e.g., butcher, baker) or manager. Direct effects do not vary by these characteristics. On overall effects, column 4 shows that ERP impacts on attrition are larger for men than women, though impacts are statistically significant and sizable for both genders. For women, ERPs reduce attrition by $10 \%$, whereas for men, ERPs reduce attrition by 30\%. Recalling that most grocery store workers are female, one possibility is that when men are in gender non-congruent roles, they may be more sensitive to feelings of respect relative to women, broadly consistent with gender role congruity theory in psychology (Eagly, 1987; Eagly \& Karau, 2002). ${ }^{38}$

To account for multiple hypothesis testing, Table 8 shows Westfall-Young adjusted pvalues. These support that the treatment heterogeneity findings are statistically significant.

Profits. Panels C-D of Table 8 show that our patterns of attrition heterogeneity imply strong heterogeneity in profits. At stores in p90 of performance or labor market quality, ERPs decrease labor costs by up to $5 \%$. For stores at p10 of either, the impact is close to 0 .

\section{$7 \quad$ Firmwide ERP Rollout}

The firm's management was pleased with the effects of the ERPs, particularly the indirect benefits, and this sentiment was shared by central HR. Because of the benefits shown in the RCT, the firm decided to roll out an ERP to the whole firm (excluding management), including grocery stores previously in the control group. Management was interested in reducing turnover further, and taking into account that referrals were increasing with bonus size in the RCT, they decided to make bonuses more attractive. The rapid firmwide rollout speaks to the importance of the indirect effects: based on our interactions with management and central HR, it is unlikely that an ERP would have been rapidly rolled out at-scale,

\footnotetext{
${ }^{37}$ In our data, differences between referrals and non-referrals are also larger in better labor markets (Table B8). However, this is far less consequential for profits compared to the indirect benefits of ERPs being larger in better labor markets.

${ }^{38}$ Other explanations are possible, but many are not supported in the data. Referrals are only $2-3 \%$ of treatment store RCT hires for both men and women, suggesting that gender difference explanations should focus on indirect effects. Estimating models from Figure 5 separately by gender, there is no evidence that ERP treatment effects on attrition increase with bonus size for either gender. This suggests that the Table 8 gender difference are unlikely to be driven by men being especially keen to make referrals in the future. Given our overall results on mechanisms, it is natural to consider potential gender differences in how ERPs affect respect.
} 
including for different jobs, had it not been for the indirect benefits of ERPs.

Under the new firmwide ERP, employees receive $€ 30$ when a referral is hired, plus an additional $€ 100$ if both parties stay 3 months. Relative to the RCT bonuses, twice as much money is paid at hire; the duration that referrer and referral must stay is 2 months lower; and total payment (€130) is higher than in all RCT arms. As the ERP was extended to nongrocery workers, namely, food production and logistics workers, we examine how ERPs work in these jobs, which are perceived as more attractive (based on surveys discussed below).

Other than covering the whole firm and using a larger bonus, the new firmwide ERP is similar to the RCT ERPs. As before, referrals are made by calling HR. The new ERP was rolled out firmwide in Jan. 2017, and, as in the RCT, was introduced using posters, letters, and meetings (Figure E1 shows posters from the rollout). As in the RCT, the firm did not accompany the new ERP by emphasizing that workers were valued or that retention was important. Unlike for the RCT, for the time period of the firmwide ERP rollout (i.e., Jan-May 2017), we only have data on who made each referral, not on who was referred.

Results on referral rates. Panel A of Table 9 summarizes the ratio of referrals made to hires across different jobs and time periods. Among grocery store workers, the ratio of referrals made to hires is $12 \%$ in the post-RCT period (Jan.-May 2017), which is an increase above the 5\% ratio in the RCT's highest bonus arm, R120. As detailed in Appendix A.14, the $12 \%$ ratio is in line with what might be expected given the RCT relationship between bonus size and referrals, and given the increased bonus generosity post-RCT. In contrast, among non-grocery workers in food production and logistics, the post-RCT ratio is $37 \%$.

Thus, while front-loading and raising the bonus increases referrals for grocery jobs, the ratio of referrals made to hires only increases to $12 \%$; this suggests that front-loading plays a role, but is unlikely the main cause of our RCT finding that ERPs modestly boost referrals for grocery jobs. Grocery jobs can be separated into cashier and non-cashier grocery jobs (e.g., butcher, assistant manager), with non-cashier jobs seen as more attractive. Table 9 shows that the referrals ratio is higher for non-cashier jobs both during and after the RCT.

Attrition. For grocery workers, the RCT impact on attrition vanishes once an ERP is rolled out to control stores. While Figure 4 uses all our data, we can also use data only from the RCT and post-RCT (i.e., no pre-RCT data) to estimate how much attrition falls in control relative to treatment stores due to the rollout. As seen in the Cox diff-in-diff in Table B12, the rollout ERP reduces attrition by $0.22 \log$ points. This mirrors the $0.20 \log$ point RCT drop in column 4 of Table 5, corroborating that ERPs reduce attrition.

Using surveys to understand the referral rate results. As during the RCT, why are there relatively few referrals for grocery jobs during the rollout? Why are there 
more referrals for non-grocery jobs, i.e., those in logistics and food production? The answer supported by surveys is that non-grocery jobs are more attractive, and people prefer to refer friends to more attractive jobs. While there are differences between grocery and non-grocery jobs other than attractiveness, these differences seem to reinforce our story. ${ }^{39}$

To learn more about how cashier jobs are regarded compared to others, we did a survey of the general population in the host country. Panel (a) of Figure 6 shows ratings of different occupations' attractiveness. Cashiers score the lowest. Non-grocery jobs at the firm, namely, those in logistics and food production, rate much higher. Instead of grocery jobs being unattractive, could results be driven by our firm being unattractive? Panel (b) of Figure 6 indicates not: our firm is well-regarded relative to other retail firms in the country.

Table A6 shows that firm managers, firm workers, and the country's general public believe that the reason why the RCT only modestly increased referrals is because grocery jobs are regarded as undesirable. In the fall 2016 manager survey, we asked an open question on why ERPs had little impact on getting referrals. Undergrads classified reasons into 10 categories. In the fall 2016 employee survey, we gave cashiers the six most popular reasons from the manager survey and asked them to rank them. Details are in Appendix A.15.

\section{Concluding Remarks and External Validity}

ERPs are a very common management practice used in hiring. ERPs may affect firms in two ways: (1) Directly, by affecting referrals in quantity or quality, or (2) Indirectly, via costs or benefits separate from affecting referrals. We use the first RCT on ERPs in a for-profit firm and the post-RCT firmwide ERP rollout to better understand these two pathways.

On (1), we find that larger bonuses increase referrals and that referrals are higher quality than non-referrals, though the share of referrals is modest, at least relative to statistics from studies of informal referrals. Despite this, the direct profit benefits of ERPs are greater than ERP costs (with an ROI of at least $30 \%$ based on direct benefits alone), so ERPs are a valuable management practice in our setting based on direct benefits alone. Larger bonuses decrease referral quality and there are more referrals for more attractive jobs. These results broadly support models where workers are altruistic toward friends (e.g., Bandiera et al., 2009; Ashraf \& Bandiera, 2018), and run contrary to popular claims that ERP bonus size does not affect referrals (Bock, 2015). A limitation of our data is that we do not observe

\footnotetext{
${ }^{39}$ For production and logistics jobs, pay is higher than for cashier jobs, making the fixed $€ 30+€ 100$ referral bonus a smaller share of pay. Another difference is that, unlike grocery jobs, not everyone's friends could work in logistics or food production. Most logistics jobs are truckdriver positions requiring a license. Food production jobs require working at a central facility (unlike the grocery store jobs which are located around the country). Such restrictions should work against generating more referrals.
} 
items scanned per minute, so we cannot evaluate direct effects with respect to this variable.

However, the most important finding of our paper concerns (2). Namely, the firm's ERPs have substantial indirect benefits. ERPs durably reduce turnover by $15-20 \%$ and these effects are present even in stores where no referrals are made. $95 \%$ of the profit gains of ERPs come from indirect benefits, thus swamping the direct benefits, and profit gains are larger in stores with better pre-RCT performance and in better local labor markets. Surveys suggest that indirect benefits arise from employees valuing being involved in the hiring process and having some say over who they would work with. The indirect effects we observe broadly support the Ellingsen \& Johannesson (2008) model of respect in the workplace. An option value mechanism, where workers stay because they hope to make referrals in the future, is much less supported. Beyond ERPs, our results help rationalize why firms seek employee participation in hiring (beyond the importance of using worker information for selection).

We are aware that - as in many other RCTs - we cannot fully rule out alternative mechanisms for the indirect effects. Our main contribution, though, is to be the first paper to measure the overall effects of ERPs, as well as the first to separately measure the direct and indirect effects of ERPs. We believe that our findings help rationalize why ERPs are a common management practice. Specifically, not only can ERPs be profitable based on the referrals they generate, but they may be highly profitable and have first-order effects on total firm labor costs even when they generate relatively few referrals.

Our 13-month RCT is quite long relative to most existing studies on management practices and impacts on attrition were as large in the last quarter of the RCT as in the first. Still, one may wonder whether indirect effects would have persisted several years into the future. We cannot experimentally answer this question because the firm rolled out ERPs firmwide after the successful RCT, reflecting the importance of the indirect effects. Instead, we can look at whether the use of the management practice persisted in the longer-run (Bloom et al., 2020). At our last discussion with management in May 2019, about 2.5 years after the RCT ended, the firm continued to use the rolled-out ERP. In informal interviews in late 2018, both executives and store managers report high satisfaction with having an ERP. According to auxiliary records from the firm, referral rates remain sizable at roughly $30 \%$ for non-grocery jobs, and remain fairly low at roughly $10 \%$ for grocery cashier jobs.

In all one-firm RCTs, it is important to consider whether conclusions are likely to be different in other contexts, even when the sample size is large. On (1), our results do not imply in general that ERPs will only modestly increase formal referrals - in fact, the postRCT ERP was very effective in motivating referrals for non-grocery jobs at our firm. In a high-skilled context, it could be that people are more responsive to bonuses, or potentially less responsive, e.g., if referral-making is instead driven by strong career motivations, as in 
the model of Ekinci (2016).

On (2), would ERPs generate sizable indirect effects in other contexts? As seen in Panel B of Table 9, we observe substantial indirect effects for different jobs and ERPs within our firm, suggesting that indirect effects could be substantial for other low-skill jobs. While the difference is not significant, overall effects are larger for non-cashier grocery workers (e.g., managers, specialists) who are more skilled relative to cashiers (see also Panel B of 8). Still, our analysis does not cover high-skill jobs, but we speculate that ERPs may still generate indirect benefits from workers valuing being involved in hiring. Of course, workers in high-skill jobs may feel more respected than workers in low-skill jobs, so it is possible that indirect benefits of ERPs would be lower. Higher skill jobs also often have much lower hiring rates, even for referred workers. On the other hand, if people are more willing to make referrals for better jobs, then there may be more opportunities to be involved in hiring for high-skill than for low-skill jobs, possibly making respect benefits larger for high-skill jobs.

To go beyond casual observation and speculation on external validity of the indirect effects, note that our Vignette Survey of US Workers (see Section 4.2.3) strongly supported that ERPs may also make US workers feel more respected. In that survey data, US workers with a bachelor's degree or higher are 10pp (s.e. $=4.0 \mathrm{pp}$ ) more likely than less-than-bachelor's workers to agree that having an ERP would make an employee feel more respected. This is consistent with the possibility that indirect benefits of ERPs occur in contexts with higherskill workers. Differences between referrals and non-referrals have been found among broad ranges of workers, including higher-skills ones (Brown et al., 2016; Burks et al., 2015), and it would not be surprising to us if indirect effects of ERPs also occur in higher-skill settings.

Future RCTs can examine the ideas from our paper in other settings, both other lowskill settings and high-skill ones, and both for ERPs and other management practices.

\section{References}

Adhvaryu, Achyuta, Molina, Teresa, \& Nyshadham, Anant. 2022. Expectations, Wage Hikes, and Worker Voice. Economic Journal, Forthcoming.

Aghion, Philippe, \& Tirole, Jean. 1997. Formal and Real Authority in Organizations. Journal of Political Economy, 105(1), 1-29.

Ashraf, Nava, \& Bandiera, Oriana. 2018. Social Incentives in Organizations. Annual Review of Economics, 10, 439-463.

Ashraf, Nava, Bandiera, Oriana, Davenport, Edward, \& Lee, Scott S. 2020. Losing Prosociality in the Quest for Talent? Sorting, Selection, and Productivity in the Delivery of Public Services. American Economic Review, 110(5), 1355-94.

Bandiera, Oriana, Barankay, Iwan, \& Rasul, Imran. 2009. Social Connections and Incentives in the Workplace: Evidence From Personnel Data. Econometrica, 77(4), 1047-1094. 
Bandiera, Oriana, Prat, Andrea, Hansen, Stephen, \& Sadun, Raffaella. 2020. CeO Behavior and Firm Performance. Journal of Political Economy, 128(4), 1325-1369.

Bartling, Björn, Fehr, Ernst, \& Herz, Holger. 2014. The Intrinsic Value of Decision Rights. Econometrica, 82(6), 2005-2039.

Bayer, Patrick, Ross, Stephen L., \& Topa, Giorgio. 2008. Place of Work and Place of Residence: Informal Hiring Networks and Labor Market Outcomes. Journal of Political Economy, 116(6), 1150-1196.

Beaman, Lori, Keleher, Niall, \& Magruder, Jeremy. 2018. Do Job Networks Disadvantage Women? Evidence from a Recruitment Experiment in Malawi. Journal of Labor Economics, 36(1), 121-157.

Benabou, Roland, \& Tirole, Jean. 2003. Intrinsic and Extrinsic Motivation. Review of Economic Studies, 70(3), 489-520.

Blader, Steven, Gartenberg, Claudine, \& Prat, Andrea. 2020. The Contingent Effect of Management Practices. Review of Economic Studies, 87(2), 721-749.

Blatter, Marc, Muehlemann, Samuel, \& Schenker, Samuel. 2012. The Costs of Hiring Skilled Workers. European Economic Review, 56(1), 20-35.

Bloom, Nicholas, \& Reenen, John Van. 2011. Human Resource Management and Productivity. Chap. 19, pages 1697-1767 of: Ashenfelter, O., \& CARD, D. (eds), Handbook of Labor Economics. Handbook of Labor Economics, vol. 4. Elsevier.

Bloom, Nicholas, \& Van Reenen, John. 2007. Measuring and Explaining Management Practices Across Firms and Countries. Quarterly Journal of Economics, 122(4), 1351-1408.

Bloom, Nicholas, Eifert, Benn, Mahajan, Aprajit, McKenzie, David, \& Roberts, John. 2013. Does Management Matter? Evidence from India. Quarterly Journal of Economics, 128(1), 1-51.

Bloom, Nicholas, Liang, James, Roberts, John, \& Ying, Zhichun Jenny. 2014. Does Working from Home Work? Evidence from a Chinese Experiment. Quarterly Journal of Economics, 130(1), 165-218.

Bloom, Nicholas, Mahajan, Aprajit, McKenzie, David, \& Roberts, John. 2020. Do Management Interventions Last? Evidence from India. American Economic Journal: Applied Economics, 12(2), 198-219.

Bock, Laszlo. 2015. Work Rules!: Insights from Inside Google That Will Transform How You Live and Lead. Twelve.

Boning, Brent, Ichniowski, Casey, \& Shaw, Kathryn. 2007. Opportunity Counts: Teams and the Effectiveness of Production Incentives. Journal of Labor Economics, 25(4), 613-650.

Borusyak, Kirill, Jaravel, Xavier, \& Spiess, Jann. 2021. Revisiting Event Study Designs: Robust and Efficient Estimation. Tech. rept. Working Paper.

Brown, Meta, Setren, Elizabeth, \& Topa, Giorgio. 2016. Do Informal Referrals Lead to Better Matches? Evidence from a Firm's Employee Referral System. Journal of Labor Economics, 34, 161-209.

Bruhn, Miriam, \& McKenzie, David. 2009. In Pursuit of Balance: Randomization in Practice in Development Field Experiments. AEJ: Applied, 1(4), 200-232.

Burks, Stephen V., Cowgill, Bo, Hoffman, Mitchell, \& Housman, Michael. 2015. The Value of Hiring through Employee Referrals. Quarterly Journal of Economics, 130(2), 805-839. 
CAI, Jing, \& WAng, ShIng-YI. 2022. Improving Management through Worker Evaluations: Evidence from Auto Manufacturing. Quarterly Journal of Economics, Forthcoming.

Calvo-Armengol, Antoni, \& Jackson, Matthew O. 2004. The Effects of Social Networks on Employment and Inequality. American Economic Review, 94(3), 426-454.

Cameron, A. Colin, Gelbach, Jonah B., \& Miller, Douglas L. 2008. Bootstrap-based improvements for inference with clustered errors. Review of Economics and Statistics, 90(3), 414-427.

CareerBullder.com. 2012. Referral Madness: How Employee Referral Programs Turn Good Employees Into Great Recruiters and Grow Your Bottom Line. CareerBuilder e-Book.

Castilla, Emilio J. 2005. Social Networks and Employee Performance in a Call Center. American Journal of Sociology, 110(5), 1243-1283.

Chetty, Raj. 2008. Moral Hazard Versus Liquidity and Optimal Unemployment Insurance. Journal of Political Economy, 116(2), 173-234.

Del Carpio, Lucia, \& Guadalupe, Maria. 2022. More Women in Tech? Evidence from a Field Experiment Addressing Social Identity. Management Science, Forthcoming.

Della Vigna, Stefano, \& Gentzkow, Matthew. 2019. Uniform Pricing in US Retail Chains. Quarterly Journal of Economics, 134(4), 2011-2084.

DeLong, Thomas, \& Vijayaraghavan, Vineeta. 2002. S.G. Cowen. HBS Case Study.

Deming, DAVID. 2017. The Growing Importance of Social Skills. Quarterly Journal of Economics, 132(4), 1593-1640.

Dube, Arindrajit, Naidu, Suresh, \& Reich, Adam. 2021. Power and Dignity In the LowWage Labor Market: Theory and Evidence from Wal-Mart Workers. Mimeo, Columbia.

Dustmann, Christian, Glitz, Albrecht, Schönberg, Uta, \& Brücker, Herbert. 2015. Referral-based Job Search Networks. Review of Economic Studies, 83(2), 514-546.

Eagly, Alice H. 1987. Sex differences in social behavior: A social-role interpretation. Psychology Press.

Eagly, Alice H., \& Karau, Steven J. 2002. Role Congruity Theory of Prejudice Toward Female Leaders. Psychological Review, 109(3), 573.

Ekinci, EmRe. 2016. Employee Referrals as a Screening Device. RAND Journal of Economics, 47(3), 688-708.

Ellingsen, Tore, \& Johannesson, Magnus. 2007. Paying Respect. Journal of Economic Perspectives, 21(4), 135-150.

Ellingsen, Tore, \& Johannesson, Magnus. 2008. Pride and Prejudice: The Human Side of Incentive Theory. American Economic Review, 98(3), 990-1008.

Englmaier, Florian, Roider, Andreas, \& Sunde, Uwe. 2017. The role of communication of performance schemes: Evidence from a field experiment. Management Science, 63(12), 40614080 .

Fernandez, Roberto M., \& Weinberg, Nancy. 1997. Sifting and Sorting: Personal Contacts and Hiring in a Retail Bank. American Sociological Review, 62(6), pp. 883-902.

Fernandez, Roberto M., Castilla, Emilio J., \& Moore, Paul. 2000. Social Capital at Work: Networks and Employment at a Phone Center. American Journal of Sociology, 105, $1288-1356$. 
Friebel, Guido, Heinz, Matthias, Krueger, Miriam, \& Zubanov, Nikolay. 2017. Team Incentives and Performance: Evidence from a Retail Chain. American Economic Review, 107(8), $2168-2203$.

Friebel, Guido, Heinz, Matthias, \& Zubanov, Nikolay. 2022. Middle Managers, Personnel Turnover, and Performance: A Long-Term Field Experiment in a Retail Chain. Management Science, 68(1), 211-229.

Gosnell, Greer K., List, John A., \& Metcalfe, Robert D. 2020. The Impact of Management Practices on Employee Productivity: A Field Experiment with Airline Captains. Journal of Political Economy, 128(4), 1195-1233.

Granovetter, Mark. 1974. Getting a Job. Cambridge, MA: Harvard University Press.

Heath, Rachel. 2018. Why Do Firms Hire Using Referrals? Evidence from Bangladeshi Garment Factories. Journal of Political Economy, 126(4), 1691-1746.

Hensvik, Lena, \& Skans, Oskar Nordström. 2016. Social networks, employee selection, and labor market outcomes. Journal of Labor Economics, 34(4), 825-867.

Hirschman, Albert O. 1970. Exit, Voice, and Loyalty: Responses to Decline in Firms, Organizations, and States. Vol. 25. Harvard University Press.

Hoffman, Mitchell. 2017. The Value of Hiring through Employee Referrals in Developed Countries. IZA World of Labor, 369, 1-8.

Ichino, Andrea, \& Riphahn, Regina T. 2005. The effect of employment protection on worker effort: Absenteeism during and after probation. Journal of the European Economic Association, 3(1), 120-143.

Ichniowski, Casey, \& Shaw, Kathryn. 1999. The Effects of Human Resource Management Systems on Economic Performance: An International Comparison of US and Japanese Plants. Management Science, 45(5), 704-721.

IChniowski, Casey, \& Shaw, Kathryn. 2012. Insider Econometrics: A Roadmap for Estimating Empirical Models of Organizational Design and Performance. R. Gibbons $\mathscr{E}$ J. Roberts, Handbook of Organizational Economics.

Ichniowski, Casey, Shaw, Kathryn, \& Prennushi, Giovanna. 1997. The Effects of Human Resource Management Practices on Productivity: A Study of Steel Finishing Lines. American Economic Review, 87(3), 291-313.

Jones, Damon, Molitor, David, \& Reif, Julian. 2019. What do Workplace Wellness Programs do? Evidence from the Illinois Workplace Wellness Study. Quarterly Journal of Economics, 134(4), 1747-1791.

Kuhn, Peter, \& Yu, Lizi. 2021. How Costly Is Turnover? Evidence from Retail. Journal of Labor Economics, 39(2), 461-496.

Kumar, Vita, Petersen, J. Andrew, \& Leone, Robert P. 2010. Driving Profitability by Encouraging Customer Referrals: Who, When, and How. Journal of Marketing, 74(5), 1-17.

Landers, Renee, Rebitzer, James B., \& Taylor, Lowell J. 1996. Rat Race Redux: Adverse Selection in the Determination of Work Hours in Law Firms. American Economic Review, 329348.

Lazear, Edward. 2000. Performance Pay and Productivity. American Economic Review, 90(5), $1346-1361$.

Mas, Alexandre, \& Moretti, Enrico. 2009. Peers at Work. American Economic Review, 
99(1), 112-45.

Milgrom, Paul, \& Roberts, John. 1990. The Economics of Modern Manufacturing: Technology, Strategy, and Organization. American Economic Review, 80(3), 511-528.

Montgomery, James D. 1991. Social Networks and Labor-Market Outcomes: Toward an Economic Analysis. American Economic Review, 81(5), 1407-18.

Nagin, Daniel, Rebitzer, James B., Sanders, Seth, \& Taylor, Lowell J. 2002. Monitoring, Motivation, and Management: The Determinants of Opportunistic Behavior in a Field Experiment. American Economic Review, 92(4), 850-873.

Oyer, Paul, \& Schaefer, Scott. 2011. Personnel Economics: Hiring and Incentives. Chap. 20, pages 1769-1823 of: Ashenfelter, O., \& CARD, D. (eds), Handbook of Labor Economics. Handbook of Labor Economics, vol. 4. Elsevier.

Pallais, Amanda, \& Sands, Emily Glassberg. 2016. Why the Referential Treatment? Evidence from Field Experiments on Referrals. Journal of Political Economy, 124(6), 1793-1828.

Rasul, Imran, \& Rogger, Daniel. 2018. Management of Bureaucrats and Public Service Delivery: Evidence from the Nigerian Civil Service. The Economic Journal, 128(608), 413-446.

Rebitzer, James B., \& Taylor, Lowell J. 2011. Extrinsic Rewards and Intrinsic Motives: Standard and Behavioral Approaches to Agency and Labor Markets. Chap. 8, pages 701-772 of: Ashenfelter, O., \& CARD, D. (eds), Handbook of Labor Economics. Handbook of Labor Economics, vol. 4. Elsevier.

ReferralPrograms.org. 2017. 2017 Referral Programs Benchmarks Report. Online report.

Ritter, Joseph A., \& Taylor, Lowell J. 1994. Workers as Creditors: Performance Bonds and Efficiency Wages. American Economic Review, 84(3), 694-704.

Scott, Neil W., McPherson, Gladys C., \& et Al. 2002. The Method of Minimization for Allocation to Clinical Trials: A Review. Controlled Clinical Trials, 23(6), $662-674$.

Shin, Seunguae, \& Eksioglu, Burak. 2015. An empirical study of RFID productivity in the U.S. retail supply chain. International Journal of Production Economics, 163, 89-96.

SHRM. 2016. Designing and Managing Successful Employee Referral Programs.

Simon, Curtis J., \& Warner, John T. 1992. Matchmaker, Matchmaker: The Effect of Old Boy Networks on Job Match Quality, Earnings, and Tenure. Journal of Labor Economics, 10(3), 306-30.

Sockin, Jason. 2021. Show Me the Amenity: Are Higher-Paying Firms Better All Around? SSRN.

Syverson, Chad. 2011. What Determines Productivity? Journal of Economic Literature, 49(2), $326-65$.

Ton, Zeynep. 2014. The Good Jobs Strategy. Houghton Mifflin Harcourt. New York, NY.

TopA, Giongio. 2011. Labor Markets and Referrals. Handbook of Social Economics, 1193-1221.

TopA, Giorgio. 2019. Social and Spatial Networks in Labour Markets. Oxford Review of Economic Policy, 35, 722-745.

Turco, Catherine J. 2016. The Conversational Firm. Columbia University Press.

Westfall, Peter, \& Young, S. Stanley. 1993. Resampling-based Multiple Testing. Vol. 279.

Young, Alwyn. 2019. Channeling Fisher: Randomization Tests and the Statistical Insignificance of Seemingly Significant Experimental Results. Quarterly Journal of Economics, 134(2), 557598. 
Figure 2: Referrals Made over Time in the RCT and Firmwide Rollout

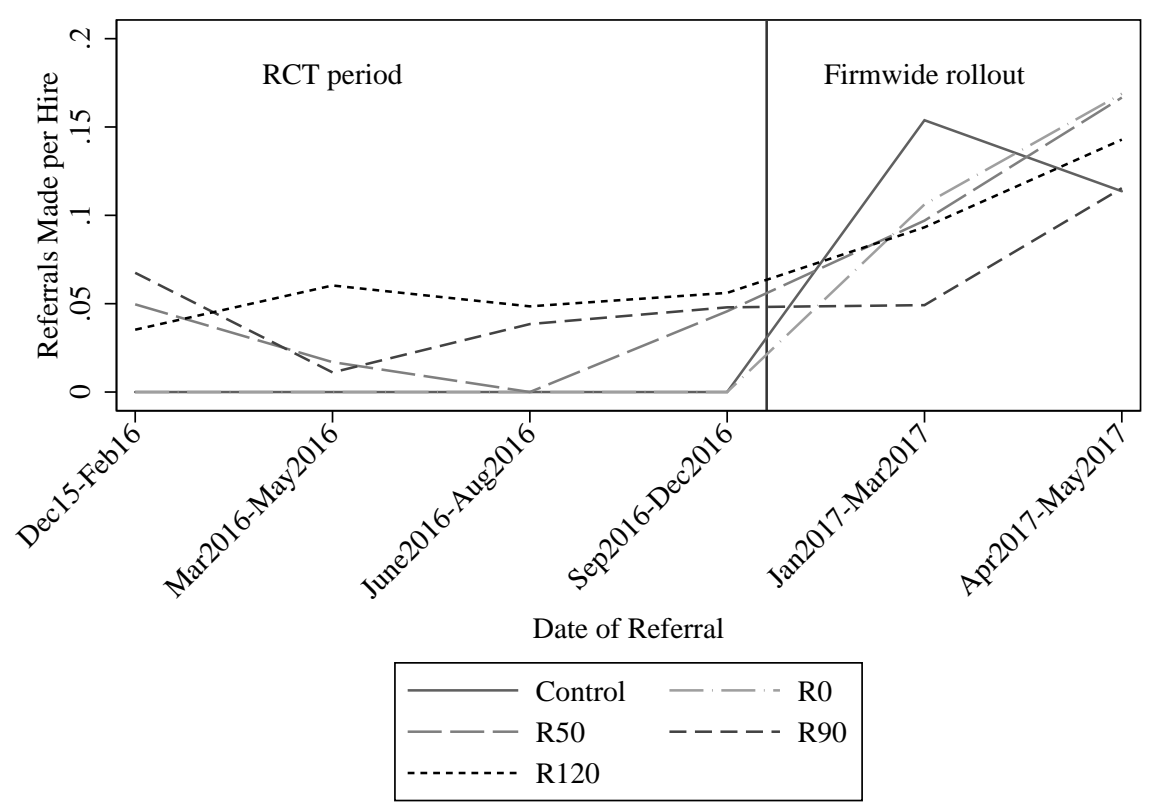

(a) Five Arms

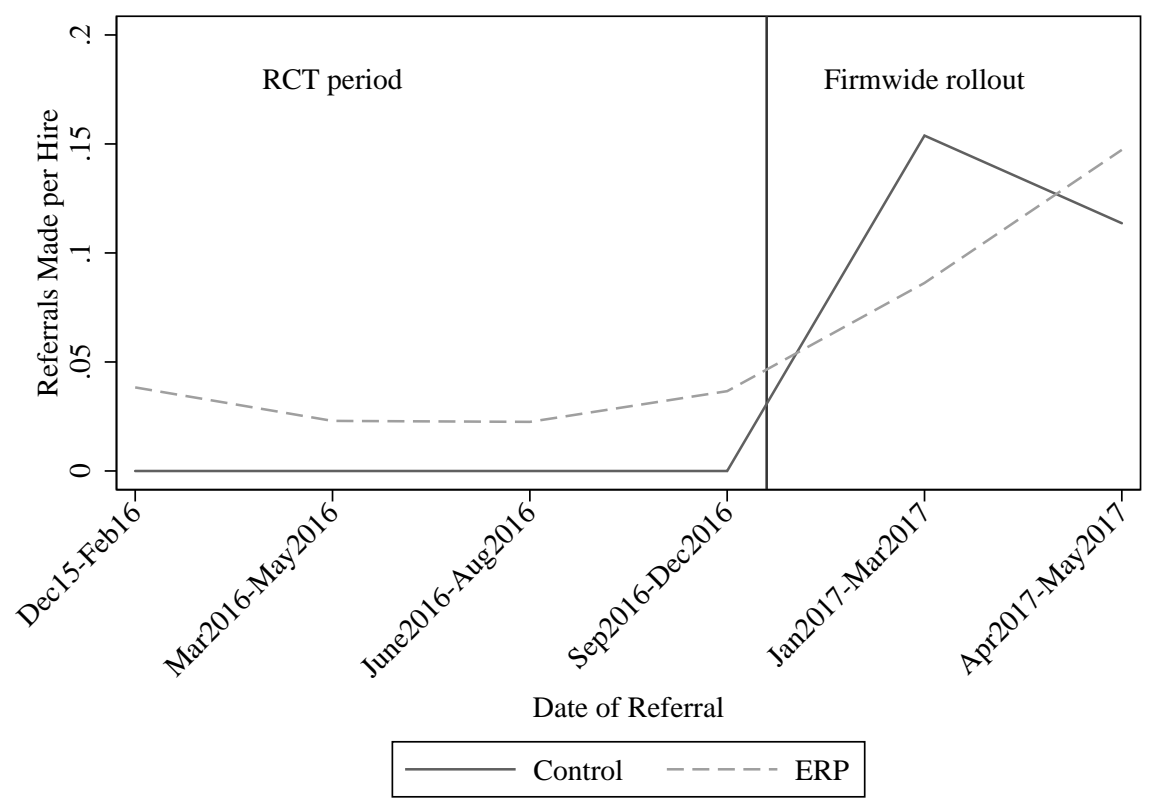

(b) ERP vs. Control

Notes: This figure shows referrals made divided by hires, and shows how this variable progresses over time across the 5 experimental arms. The vertical line is located in between $2016 \mathrm{~m} 9-2016 \mathrm{~m} 12$ and 2017m1-2017m3, and separates the RCT period from the firmwide rollout. Panel (a) shows the 5 arms and panel (b) shows control vs. ERP stores. In panel (b), over the four quarters of the RCT, the number of referrals made is $24,17,21$, and 26 , whereas the ratio of referrals per hire is $3.8 \%, 2.3 \%, 2.3 \%$, and $3.7 \%$. The ratio is lower in June-August 2016 because there is more hiring then. 
Figure 3: Survival Curve Comparisons

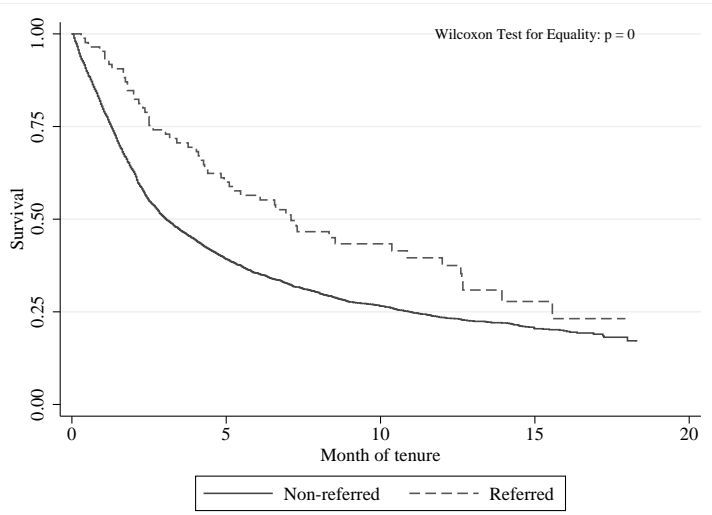

(a) Referrals vs. Non-referrals

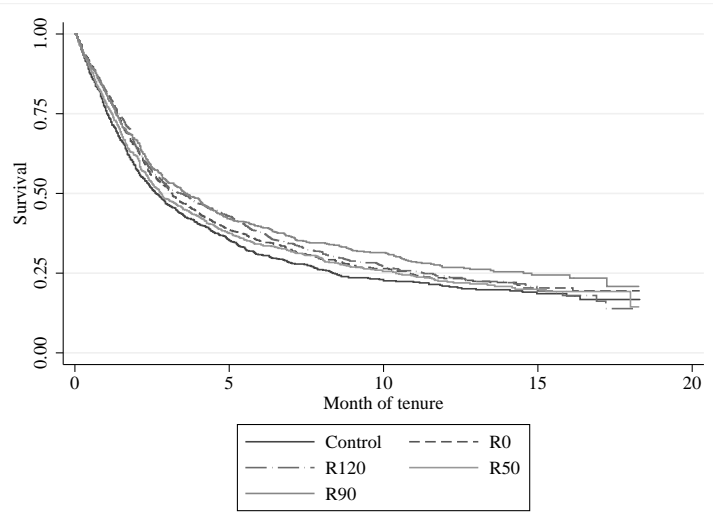

(c) Survival of Non-Referrals by Bonus Group

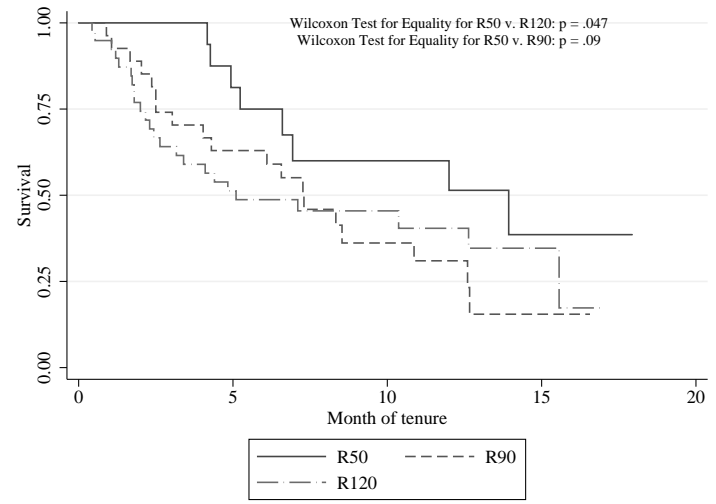

(b) Referral Survival by Bonus Level

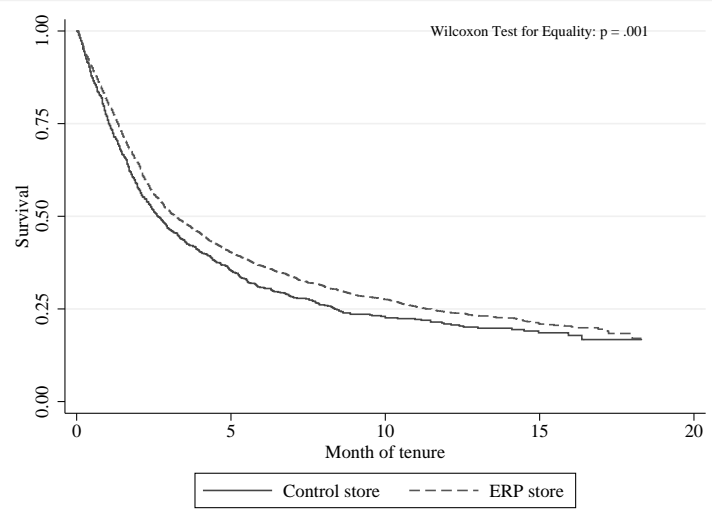

(d) Survival of Non-Referrals, by ERP Stores vs. Control

Notes: This figure presents different survival comparisons. Panel (a) compares referrals and non-referrals in terms of survival. Panel (b) analyzes the survival of referrals across the three positive bonus groups. Panel (c) analyzes the survival of non-referrals according to the five randomized treatments (Control, R0, R50, R90, R120). Panel (d) repeats panel (c) but splits according to whether there is an ERP, thereby grouping R0, R50, R90, and R120 together vs. Control. We restrict attention to workers hired during the RCT (December 2015-December 2016), but we follow them here through the end of our personnel data in May 2017. To show survival curves with granularity, spells are shown based on day of hire. 
Figure 4: Event Studies: Having an ERP Lowers Attrition During the RCT, and the Effect is Reversed Once an ERP is Rolled out to Control Stores. ERP Effects are Similar in Stores with No Referrals During the RCT.

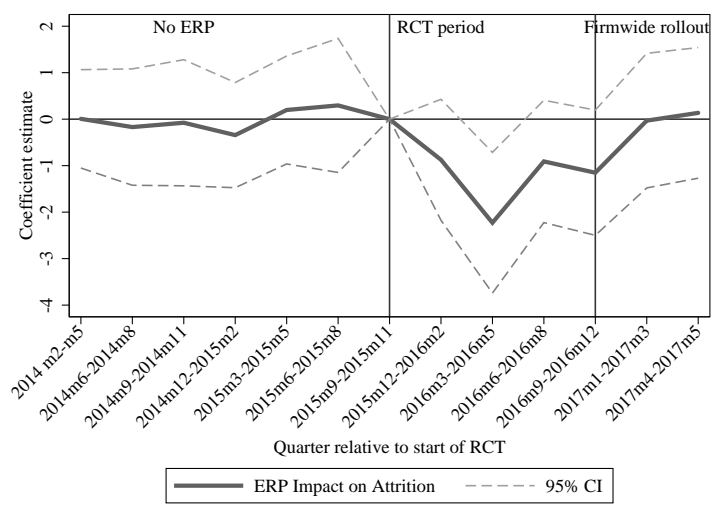

(a) ERP Impact in All Stores

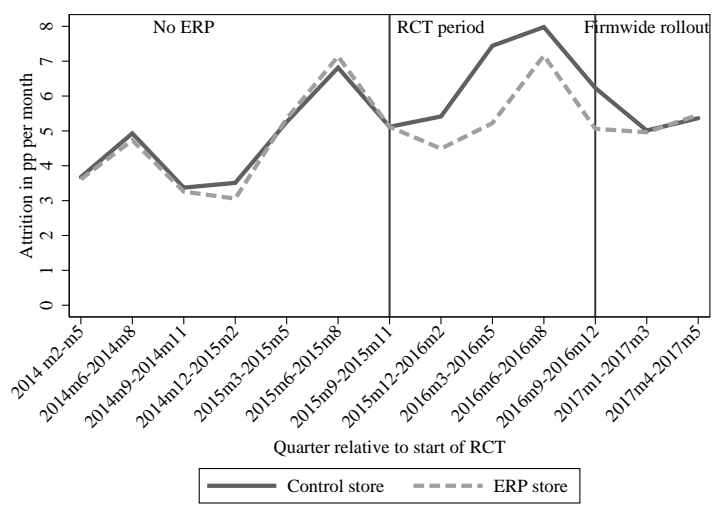

(c) ERP vs. Control in All Stores

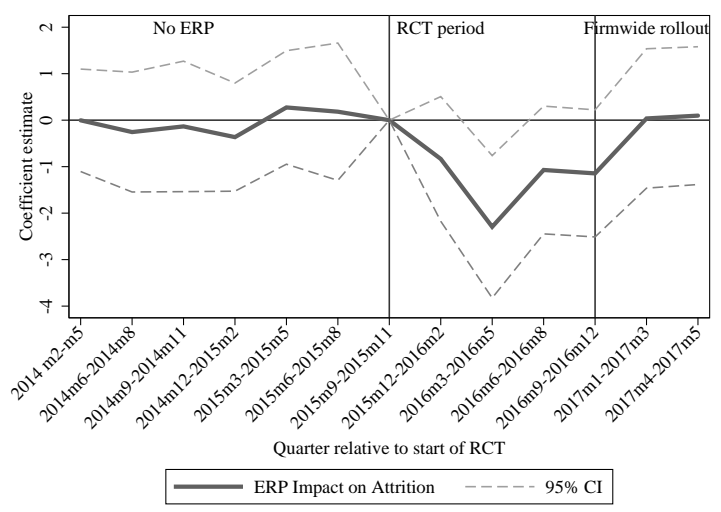

(b) ERP Impact in Stores with No Referrals

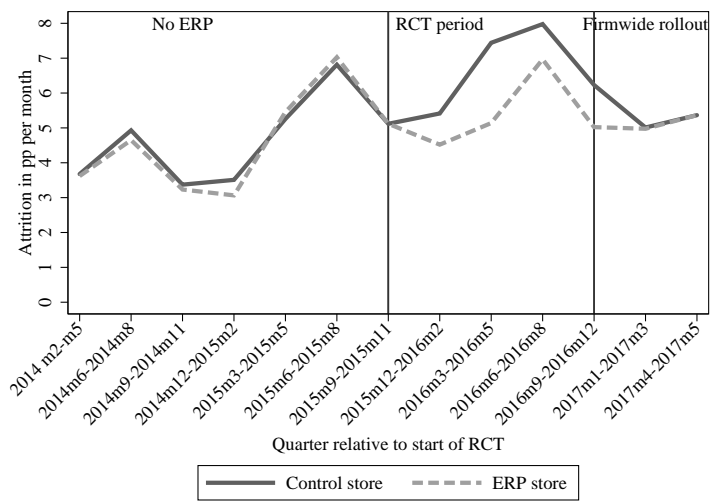

(d) ERP vs. Control, Stores with No Refs

Notes: Panel (a) analyzes the impact of having a randomly assigned ERP (i.e., one of the four RCT ERPs) on attrition. The solid line denotes the coefficient estimates, with the dotted lines denoting the $95 \%$ confidence intervals. The regression equation used to plot the event study appears in equation (6). Controls are the same as in columns 3-4 of Table 5 except tenure controls here are a probation period dummy, plus linear terms in tenure on both sides of 3 months. The omitted quarter is the last quarter before the RCT, 2015m9-2015m11. Panel (b) repeats Panel (a) while restricting attention to workers in stores where no referrals are ever made during the RCT. Panels (c) and (d) perform regressions separately for ERP and Control stores. We regress attrition on quarter-year dummies (where the quarter before the RCT, 2015m9-2015m11, is the omitted category), as well as store dummies, tenure controls (probation period dummy, plus linear terms in tenure on both sides of 3 months), gender (including a dummy for gender being missing), and a dummy for being a cashier. All coefficients shown are normalized relative to Control store mean attrition in the quarter before the RCT (i.e., we show the quarter-year regression coefficients plus Control store mean attrition in 2015m9-2015m11). Panel (c) uses all stores. Panel (d) repeats panel (c) restricting attention to workers in stores where no referrals are ever made during the RCT. Note that some "quarters" are not three months, reflecting that the pre-RCT, RCT, and post-RCT periods are not multiples of three months. We divide the 13 months of the RCT into Dec. 2015-Feb. 2016, March 2016-May 2016, June 2016-Aug. 2016, and Sept. 2016-Dec. 2016, but results are similar if have 4 months for the first quarter instead of the last quarter. The RCT actually begins toward the end of $2015 \mathrm{~m} 11$ (on $11 / 20 / 2015$ ), but results are robust to dropping $2015 \mathrm{~m} 11$. 
Figure 5: The Impact of ERPs on Employee Attrition Does Not Significantly Vary with the Level of the Referral Bonus (Cox Models)

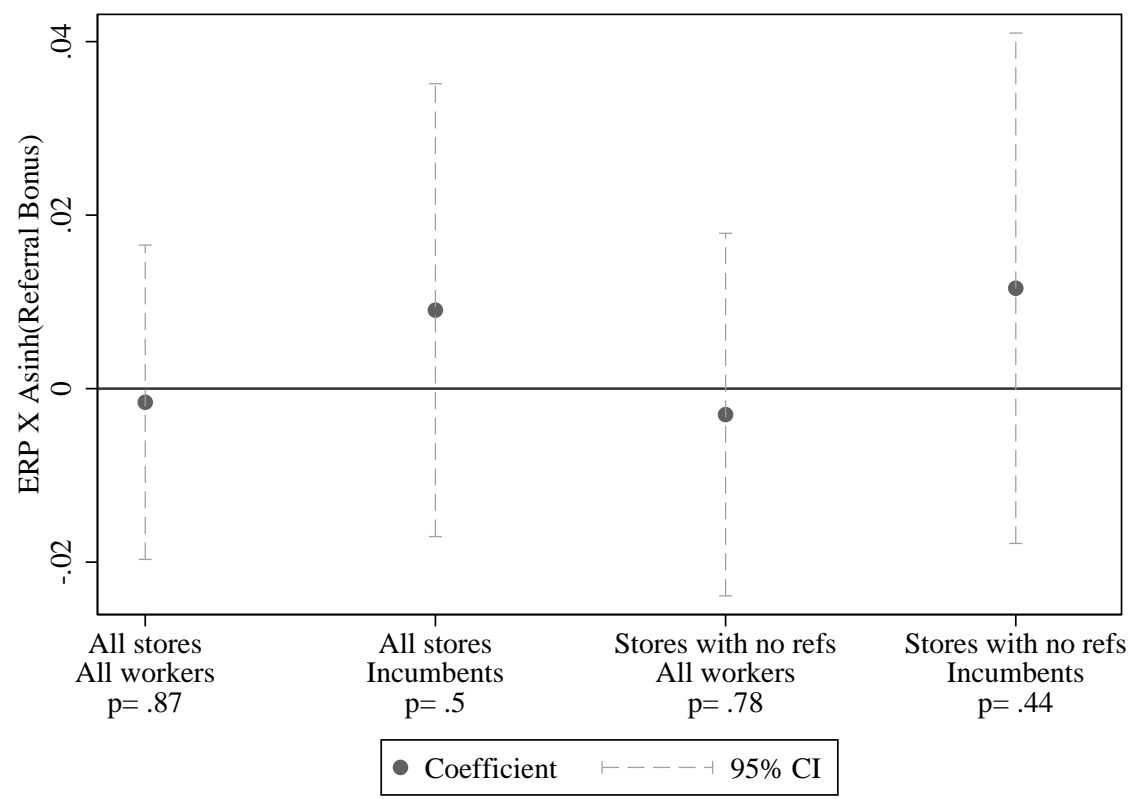

(a) The Interaction Term, ERP X Inverse Hyperbolic Sine of the Bonus, is Indistinguishable From Zero

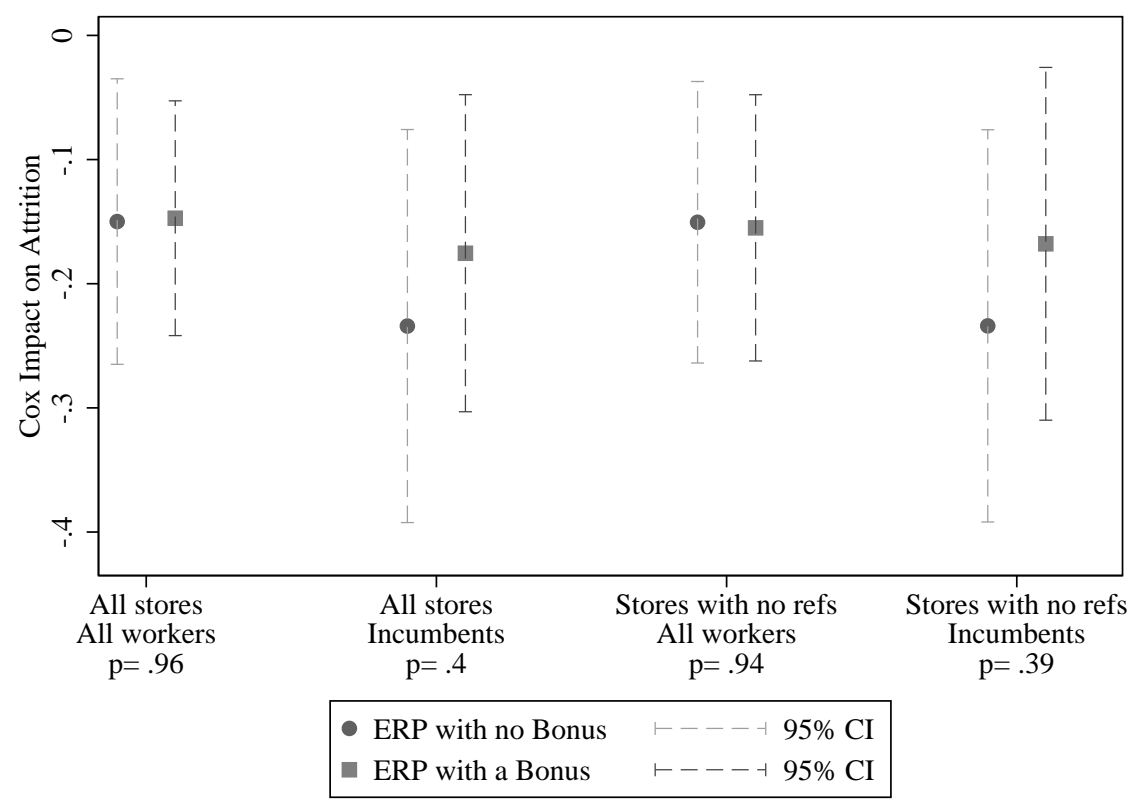

(b) No Significant Difference Between the No Bonus and Positive Bonus ERPs

Notes: Using Cox models, this figure shows how the impact of ERPs on attrition varies with the level of the referral bonus. Panel (a) estimates models from equation (7). Controls are the same as in Table 5. The first and second comparisons are based on columns 1 and 7 of Table 5, respectively. The third and fourth comparisons are similar to the first and second, but restrict to stores where there were no referrals made during the RCT; they are based on columns 1 and 7 of Table B6, respectively. The bonus size is 0 for control stores and R0 stores. Each p-value corresponds to the test that the interaction term equals 0. Panel (b) estimates models similar to those in Table 5 except we lump R50, R90, and R120 together to create a single dummy for an ERP treatment paying a positive bonus. Thus, we have two key regressors: ERP with no Bonus (i.e., the R0 dummy) and ERP with a Bonus (i.e., the sum of the Bignmies, R50+R90+R120). Each p-value corresponds to the test that the two key coefficients are equal. 


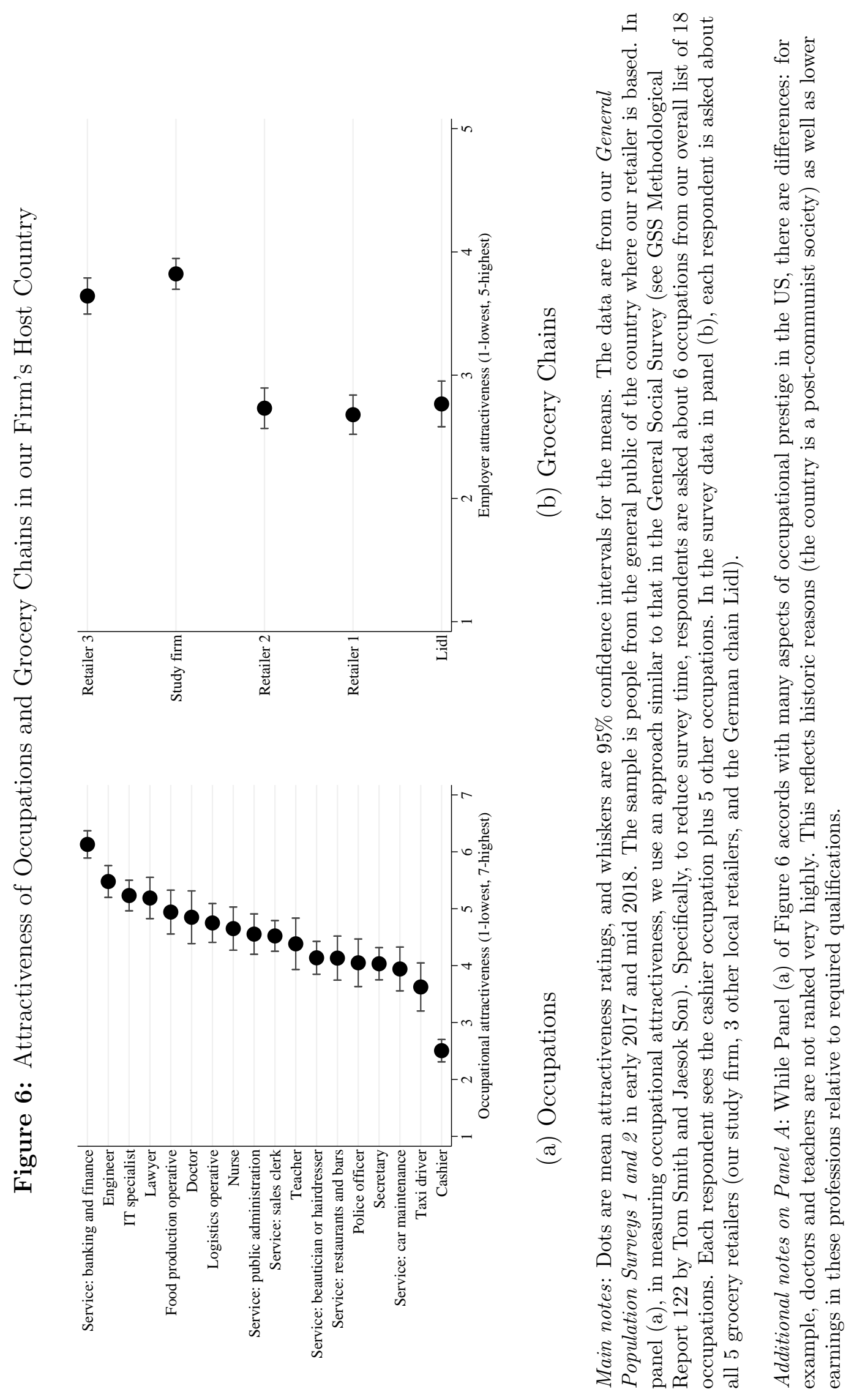


Table 1: Comparing Pre-Treatment Store Means across the Treatment Groups $(N=238$ stores): Randomization Check

\begin{tabular}{|c|c|c|c|c|c|c|c|c|}
\hline & \multicolumn{6}{|c|}{ Comparing All 5 Arms } & \multicolumn{2}{|c|}{ ERP vs. Contro } \\
\hline & $\begin{array}{l}\text { Control } \\
(1)\end{array}$ & $\begin{array}{l}\text { R0 } \\
(2)\end{array}$ & $\begin{array}{c}\mathrm{R} 50 \\
(3)\end{array}$ & $\begin{array}{l}\mathrm{R} 90 \\
(4)\end{array}$ & $\begin{array}{c}\mathrm{R} 120 \\
(5)\end{array}$ & $\begin{array}{c}\text { p-val } \\
(6)\end{array}$ & $\begin{array}{c}\mathrm{ERP} \\
(7)\end{array}$ & $\begin{array}{c}\text { p-val } \\
(8)\end{array}$ \\
\hline \multicolumn{9}{|c|}{ Outcome Variables, All at the Monthly Level } \\
\hline Monthly hires & $\begin{array}{c}1.05^{* * *} \\
(0.12)\end{array}$ & $\begin{array}{c}0.13 \\
(0.18)\end{array}$ & $\begin{array}{c}0.12 \\
(0.20)\end{array}$ & $\begin{array}{c}0.16 \\
(0.20)\end{array}$ & $\begin{array}{c}0.34 \\
(0.27)\end{array}$ & 0.77 & $\begin{array}{c}0.19 \\
(0.15)\end{array}$ & 0.22 \\
\hline Attrition rate $(\mathrm{x} 100)$ & $\begin{array}{c}5.01^{* * *} \\
(0.42)\end{array}$ & $\begin{array}{c}0.29 \\
(0.54)\end{array}$ & $\begin{array}{c}0.32 \\
(0.57)\end{array}$ & $\begin{array}{c}0.30 \\
(0.58)\end{array}$ & $\begin{array}{c}0.27 \\
(0.59)\end{array}$ & 0.98 & $\begin{array}{c}0.29 \\
(0.46)\end{array}$ & 0.52 \\
\hline Quit rate $(\mathrm{x} 100)$ & $\begin{array}{c}5.40^{* * *} \\
(0.51)\end{array}$ & $\begin{array}{c}0.35 \\
(0.76)\end{array}$ & $\begin{array}{l}-0.17 \\
(0.69)\end{array}$ & $\begin{array}{c}0.55 \\
(0.72)\end{array}$ & $\begin{array}{l}-0.09 \\
(0.69)\end{array}$ & 0.82 & $\begin{array}{c}0.16 \\
(0.56)\end{array}$ & 0.78 \\
\hline Fire rate $(\mathrm{x} 100)$ & $\begin{array}{c}0.78^{* * *} \\
(0.18)\end{array}$ & $\begin{array}{c}0.15 \\
(0.25)\end{array}$ & $\begin{array}{c}0.05 \\
(0.23)\end{array}$ & $\begin{array}{c}0.03 \\
(0.23)\end{array}$ & $\begin{array}{c}0.19 \\
(0.24)\end{array}$ & 0.92 & $\begin{array}{c}0.10 \\
(0.19)\end{array}$ & 0.59 \\
\hline Absences per worker & $\begin{array}{c}1.23^{* * *} \\
(0.08)\end{array}$ & $\begin{array}{c}0.10 \\
(0.12)\end{array}$ & $\begin{array}{l}-0.10 \\
(0.13)\end{array}$ & $\begin{array}{l}-0.08 \\
(0.11)\end{array}$ & $\begin{array}{c}0.10 \\
(0.11)\end{array}$ & 0.25 & $\begin{array}{c}0.00 \\
(0.09)\end{array}$ & 0.96 \\
\hline Sales in 000's of $€$ & $\begin{array}{c}209.78^{* * *} \\
(23.34)\end{array}$ & $\begin{array}{c}1.08 \\
(30.01)\end{array}$ & $\begin{array}{l}-16.13 \\
(31.07)\end{array}$ & $\begin{array}{l}-2.22 \\
(32.16)\end{array}$ & $\begin{array}{c}0.71 \\
(33.82)\end{array}$ & 0.97 & $\begin{array}{l}-4.14 \\
(25.56)\end{array}$ & 0.87 \\
\hline Log(Sales per worker) & $\begin{array}{c}9.01^{* * *} \\
(0.02)\end{array}$ & $\begin{array}{l}-0.01 \\
(0.03)\end{array}$ & $\begin{array}{l}-0.02 \\
(0.03)\end{array}$ & $\begin{array}{l}-0.02 \\
(0.03)\end{array}$ & $\begin{array}{c}0.01 \\
(0.03)\end{array}$ & 0.86 & $\begin{array}{l}-0.01 \\
(0.02)\end{array}$ & 0.67 \\
\hline $\begin{array}{l}\log (\text { Operational profit } \\
\text { per worker })\end{array}$ & $\begin{array}{c}7.44^{* * *} \\
(0.03)\end{array}$ & $\begin{array}{c}0.00 \\
(0.04)\end{array}$ & $\begin{array}{l}-0.02 \\
(0.05)\end{array}$ & $\begin{array}{l}-0.02 \\
(0.05)\end{array}$ & $\begin{array}{l}-0.01 \\
(0.05)\end{array}$ & 0.99 & $\begin{array}{l}-0.01 \\
(0.03)\end{array}$ & 0.68 \\
\hline Log(Shrinkage ratio) & $\begin{array}{c}-3.58^{* * *} \\
(0.03)\end{array}$ & $\begin{array}{c}0.03 \\
(0.05)\end{array}$ & $\begin{array}{l}-0.03 \\
(0.05)\end{array}$ & $\begin{array}{c}0.00 \\
(0.05)\end{array}$ & $\begin{array}{l}-0.03 \\
(0.05)\end{array}$ & 0.72 & $\begin{array}{l}-0.01 \\
(0.04)\end{array}$ & 0.83 \\
\hline \multicolumn{9}{|l|}{ Non-outcome Variables } \\
\hline Head count & $\begin{array}{c}25.11^{* * *} \\
(2.70)\end{array}$ & $\begin{array}{c}0.58 \\
(3.55)\end{array}$ & $\begin{array}{l}-0.98 \\
(3.76)\end{array}$ & $\begin{array}{c}0.75 \\
(3.93)\end{array}$ & $\begin{array}{c}0.08 \\
(3.89)\end{array}$ & 0.99 & $\begin{array}{c}0.11 \\
(2.99)\end{array}$ & 0.97 \\
\hline In big city & $\begin{array}{c}0.37^{* * *} \\
(0.07)\end{array}$ & $\begin{array}{c}0.11 \\
(0.10)\end{array}$ & $\begin{array}{c}0.07 \\
(0.10)\end{array}$ & $\begin{array}{c}0.09 \\
(0.10)\end{array}$ & $\begin{array}{l}-0.06 \\
(0.10)\end{array}$ & 0.42 & $\begin{array}{c}0.05 \\
(0.08)\end{array}$ & 0.51 \\
\hline Lidl store nearby & $\begin{array}{c}0.24^{* * *} \\
(0.06)\end{array}$ & $\begin{array}{c}0.05 \\
(0.09)\end{array}$ & $\begin{array}{c}0.03 \\
(0.09)\end{array}$ & $\begin{array}{l}-0.05 \\
(0.09)\end{array}$ & $\begin{array}{l}-0.05 \\
(0.09)\end{array}$ & 0.66 & $\begin{array}{l}-0.00 \\
(0.07)\end{array}$ & 0.95 \\
\hline $\begin{array}{l}2015 \text { unemployment rate in } \\
\text { a store's municipality }\end{array}$ & $\begin{array}{c}7.85 * * * \\
(0.33)\end{array}$ & $\begin{array}{l}-0.26 \\
(0.45)\end{array}$ & $\begin{array}{l}-0.44 \\
(0.48)\end{array}$ & $\begin{array}{c}0.06 \\
(0.49)\end{array}$ & $\begin{array}{c}0.06 \\
(0.48)\end{array}$ & 0.79 & $\begin{array}{l}-0.15 \\
(0.37)\end{array}$ & 0.69 \\
\hline Store size (square meters) & $\begin{array}{c}648.55^{* * *} \\
(58.78)\end{array}$ & $\begin{array}{c}13.31 \\
(75.23)\end{array}$ & $\begin{array}{l}-35.44 \\
(79.57)\end{array}$ & $\begin{array}{c}4.29 \\
(82.38)\end{array}$ & $\begin{array}{l}-15.70 \\
(79.43)\end{array}$ & 0.97 & $\begin{array}{l}-8.38 \\
(64.10)\end{array}$ & 0.90 \\
\hline $\begin{array}{l}\text { Share of store workers } \\
\text { who are cashiers }\end{array}$ & $\begin{array}{c}77.76^{* * *} \\
(1.08)\end{array}$ & $\begin{array}{c}1.87 \\
(1.52)\end{array}$ & $\begin{array}{c}2.26 \\
(1.53)\end{array}$ & $\begin{array}{c}1.02 \\
(1.55)\end{array}$ & $\begin{array}{c}1.54 \\
(1.47)\end{array}$ & 0.62 & $\begin{array}{c}1.68 \\
(1.20)\end{array}$ & 0.16 \\
\hline Share female & $\begin{array}{c}88.93^{* * *} \\
(1.18)\end{array}$ & $\begin{array}{l}-1.14 \\
(1.70)\end{array}$ & $\begin{array}{c}0.60 \\
(1.66)\end{array}$ & $\begin{array}{l}-0.49 \\
(1.75)\end{array}$ & $\begin{array}{c}0.51 \\
(1.72)\end{array}$ & 0.84 & $\begin{array}{l}-0.13 \\
(1.33)\end{array}$ & 0.92 \\
\hline Worker age & $\begin{array}{c}32.31^{* * *} \\
(0.63)\end{array}$ & $\begin{array}{l}0.12 \\
(.81)\end{array}$ & $\begin{array}{c}0.36 \\
(0.85)\end{array}$ & $\begin{array}{l}-0.57 \\
(0.88)\end{array}$ & $\begin{array}{c}0.68 \\
(0.81)\end{array}$ & 0.62 & $\begin{array}{c}0.15 \\
(0.69)\end{array}$ & 0.83 \\
\hline
\end{tabular}

Notes: This table compares pre-RCT store-level characteristics across the different treatment arms. Each row contains two store-level OLS regressions $(N=238)$, with robust standard errors in parentheses. In columns 1-6, we regress characteristics on dummies for the four treatment arms. The estimated constant corresponds to the mean in the control group. The p-value in column 6 corresponds to the test for joint significance of the treatment dummies. Columns 7-8 lump all treatment stores together and compare ERP versus Control stores. There are 46 stores in the control group, and 48 stores in each of the 4 treatment groups. "Head count" is the number of employees in a store. The attrition rate, quit rate, and fire rate are the average monthly rates, multiplied by 100 for ease of presentation. The division of attrition into quits and fires is only available starting in $2015 \mathrm{~m} 4$, whereas the attrition data go back to $2014 \mathrm{~m} 2$. The randomization was not stratified, but as noted in footnote 17, we drew randomization allocations numerous times, with an eye for detecting balance on several variables. The pre-RCT period is $2014 \mathrm{~m} 2-2015 \mathrm{~m} 10$ (excluding $2015 \mathrm{~m} 11$ since the RCT began midway through that month). * significant at $10 \% ; * *$ significant at $5 \% ; * * *$ significant at $1 \%$ 


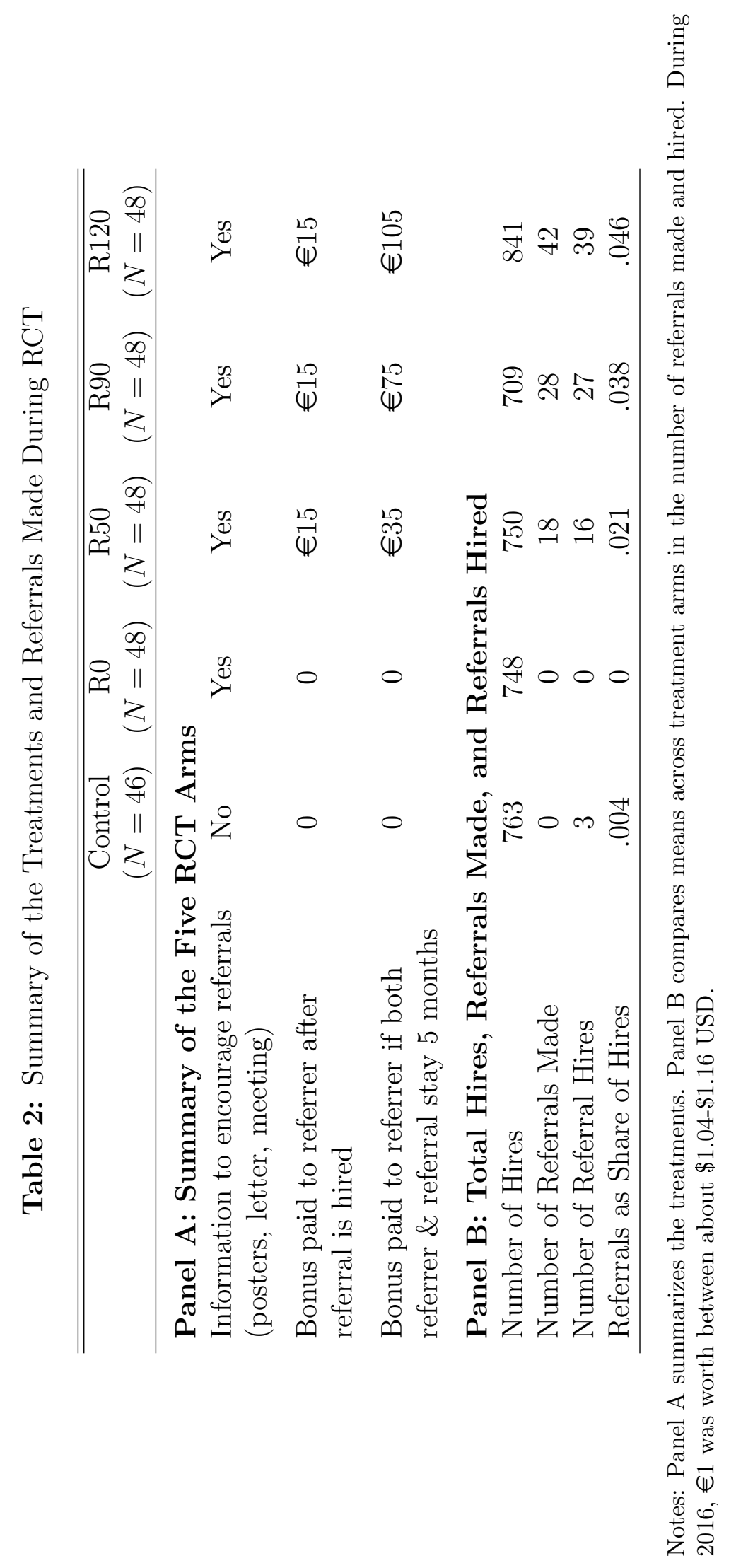




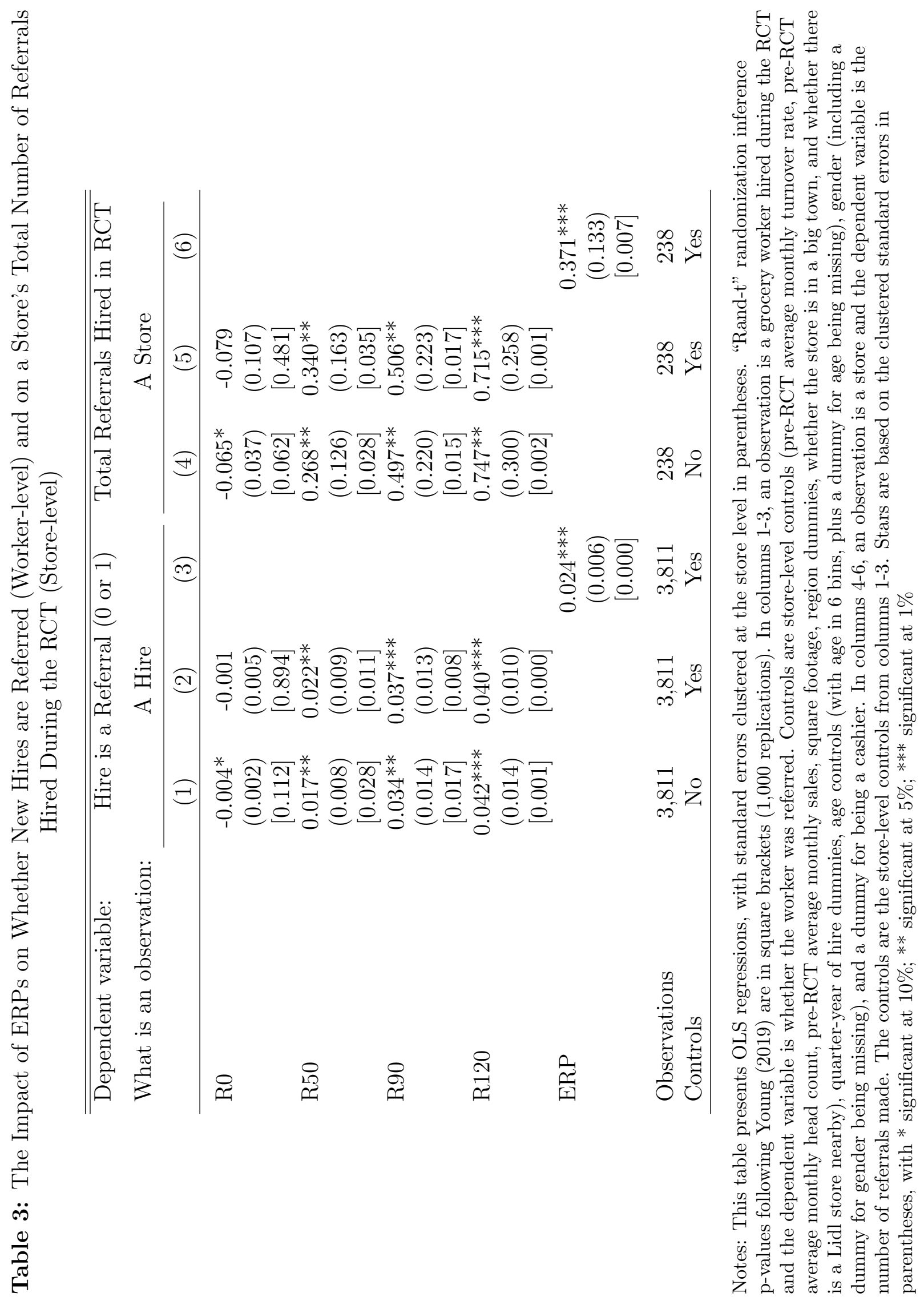




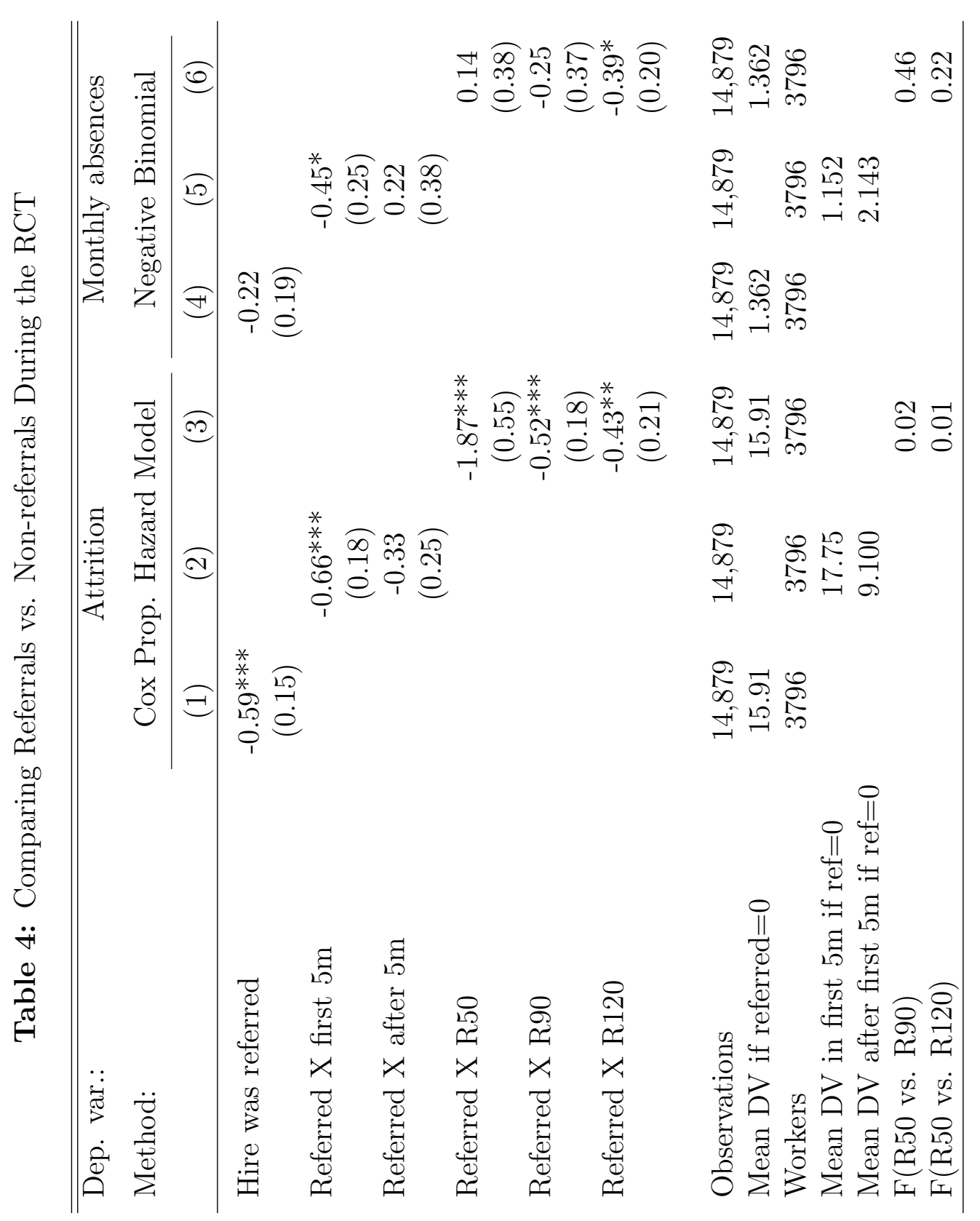

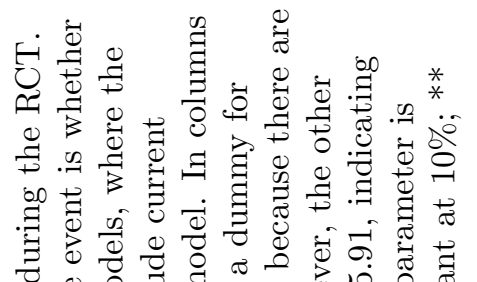

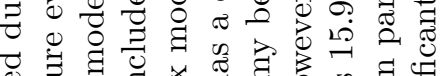

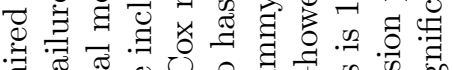

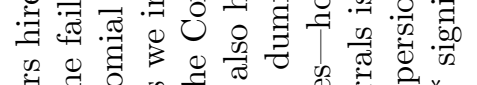

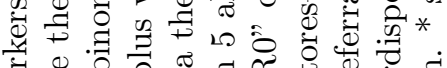

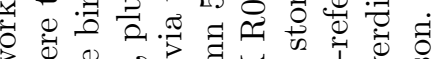

अ

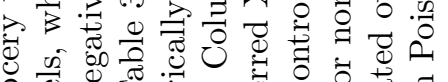

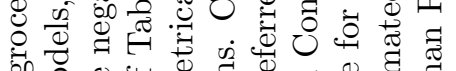

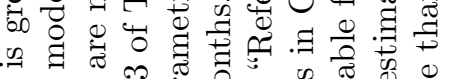

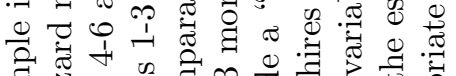

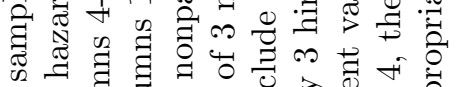

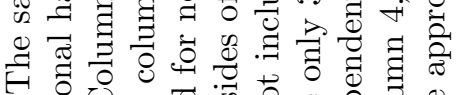

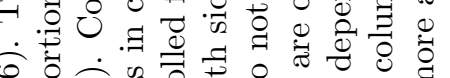

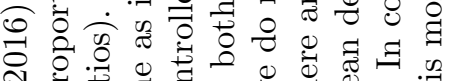

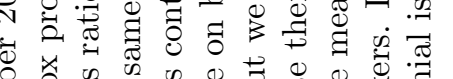

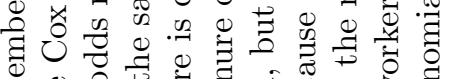

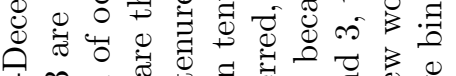

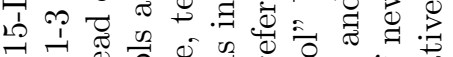

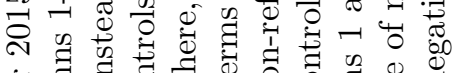

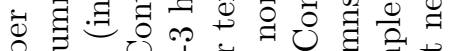

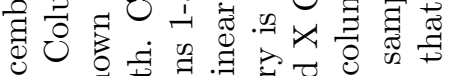

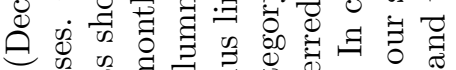

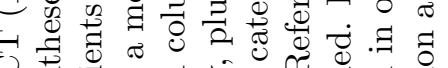

诃

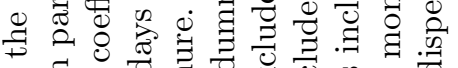

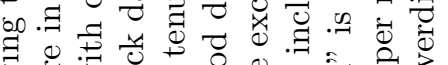

青荡荡

च च

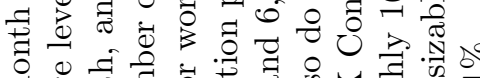

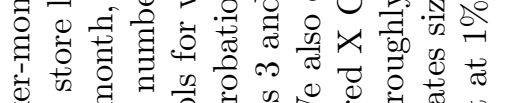

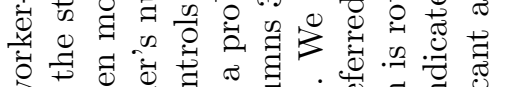

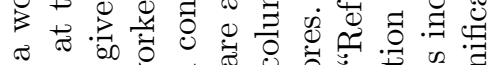

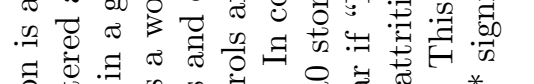

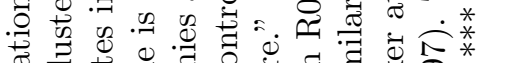

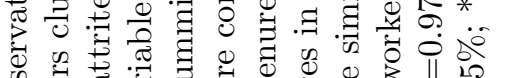

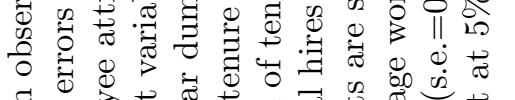

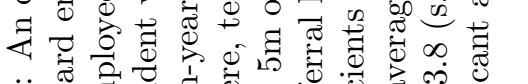

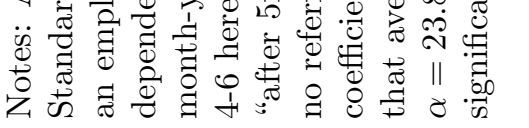




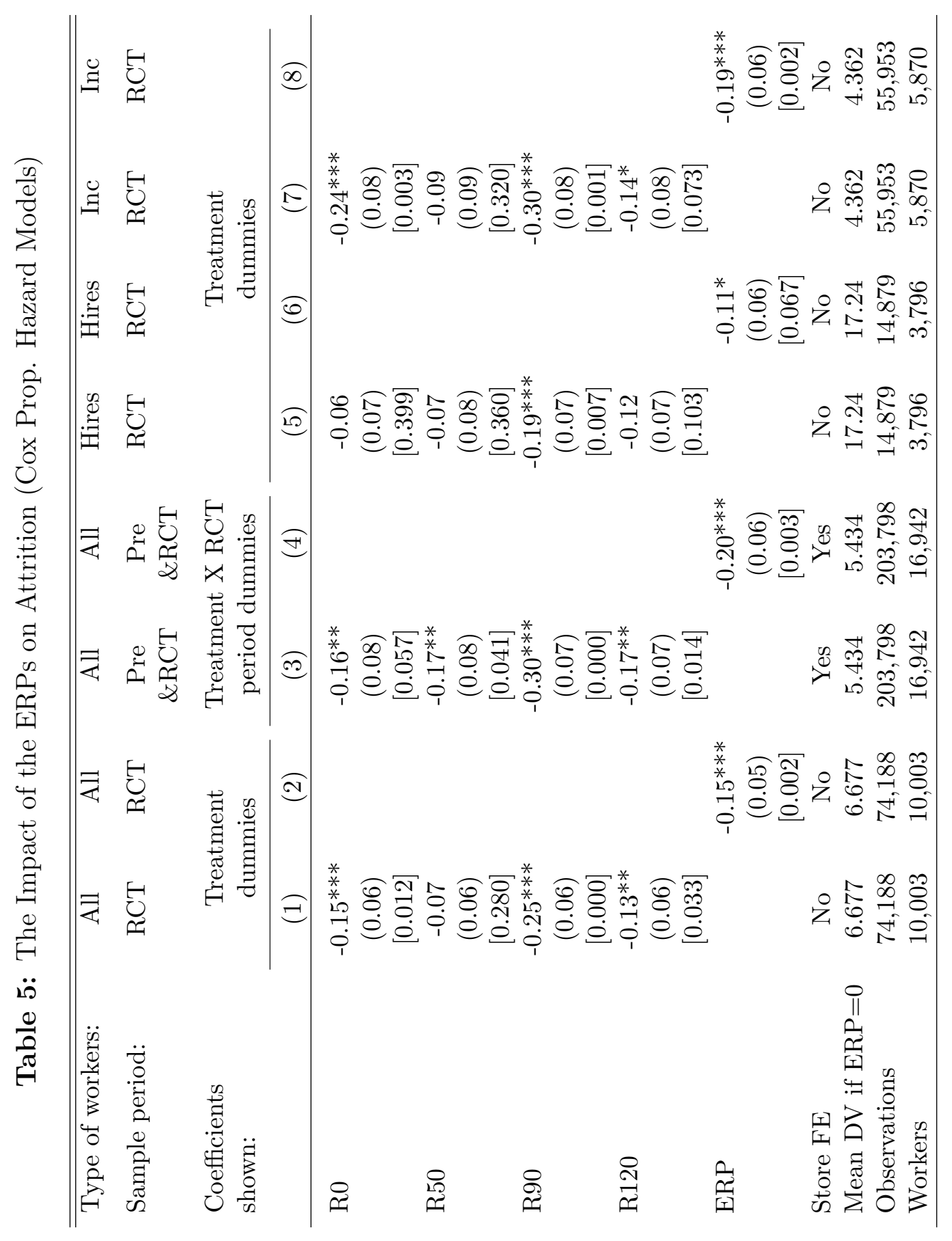

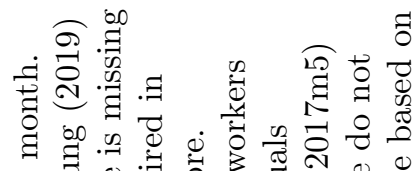

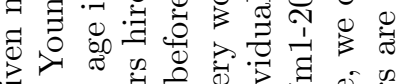
कo 00000 त त्र

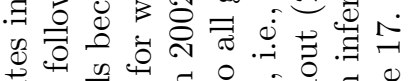

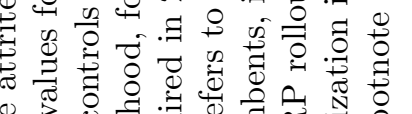

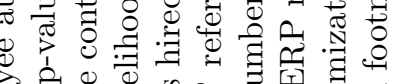

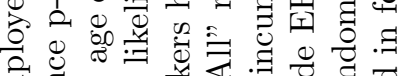

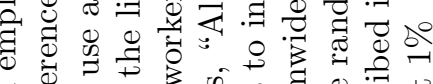
击光 可

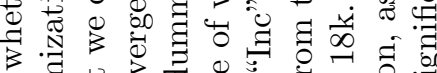

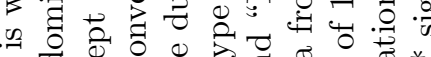

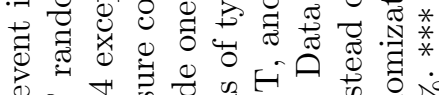
ن

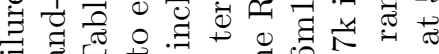
बत

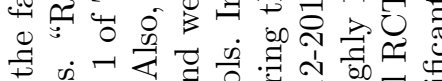
ه

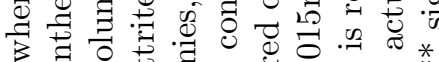

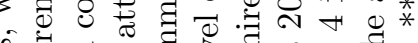

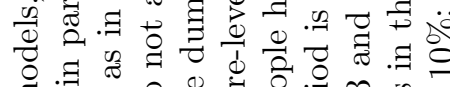
a

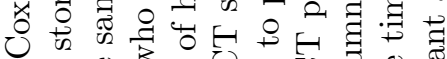

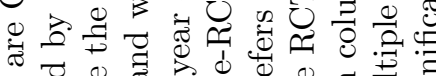

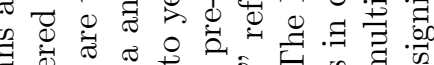

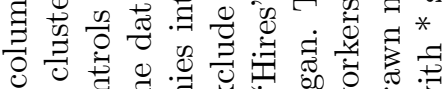
O ये

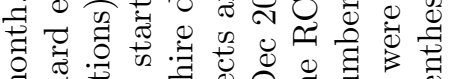

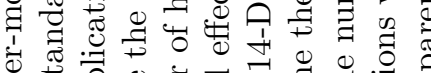

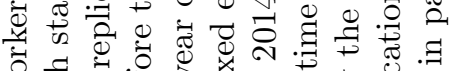

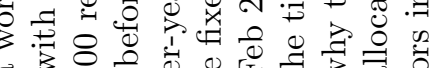
उ 电可

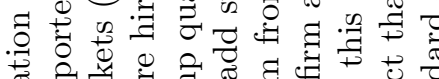

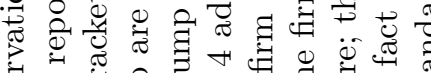

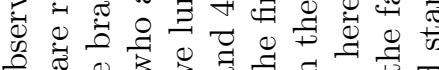

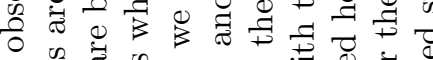

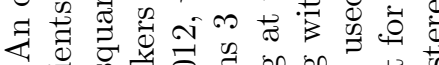

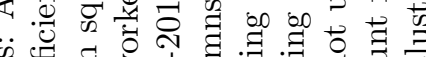
ن

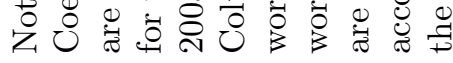




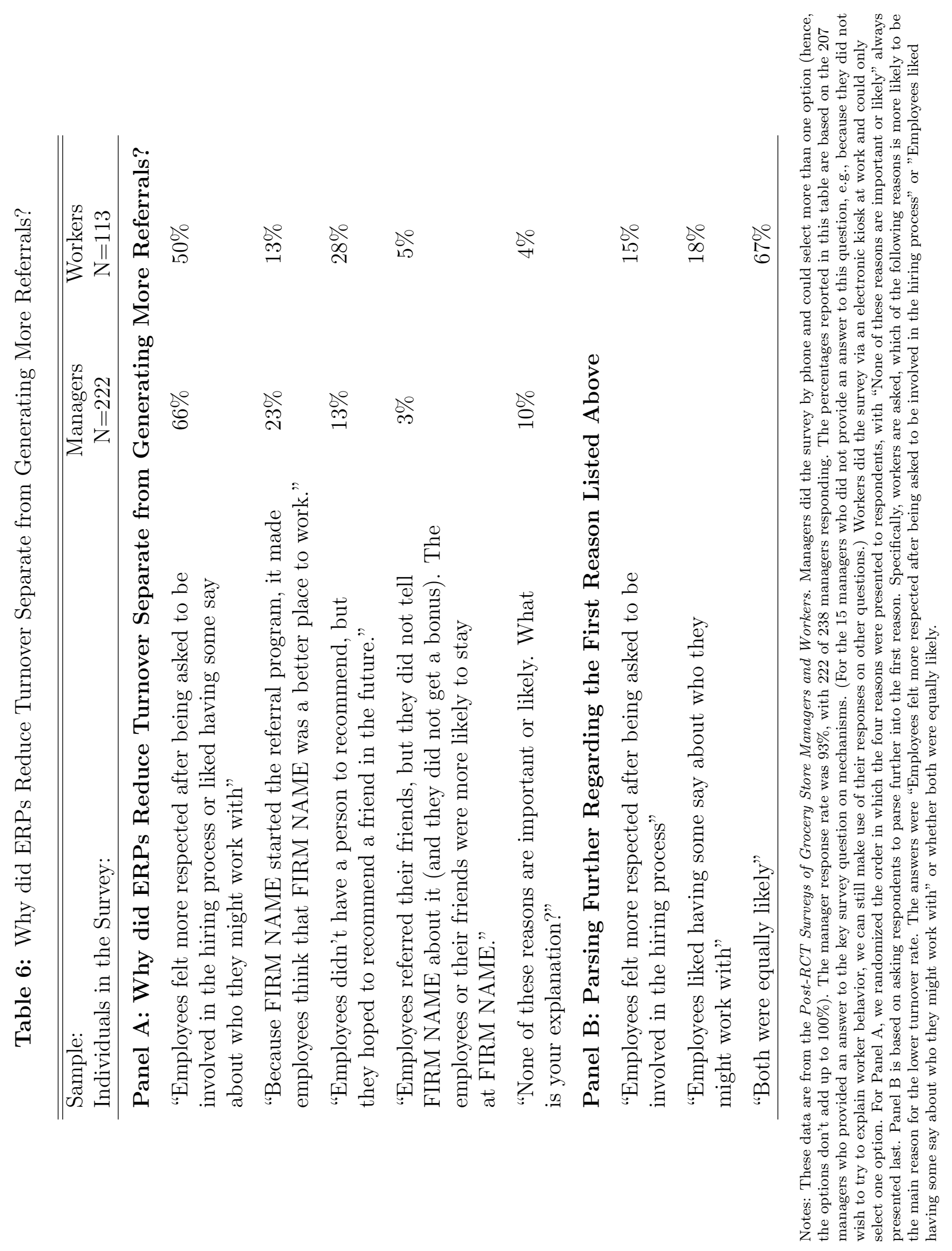


Table 7: Profits from the ERPs

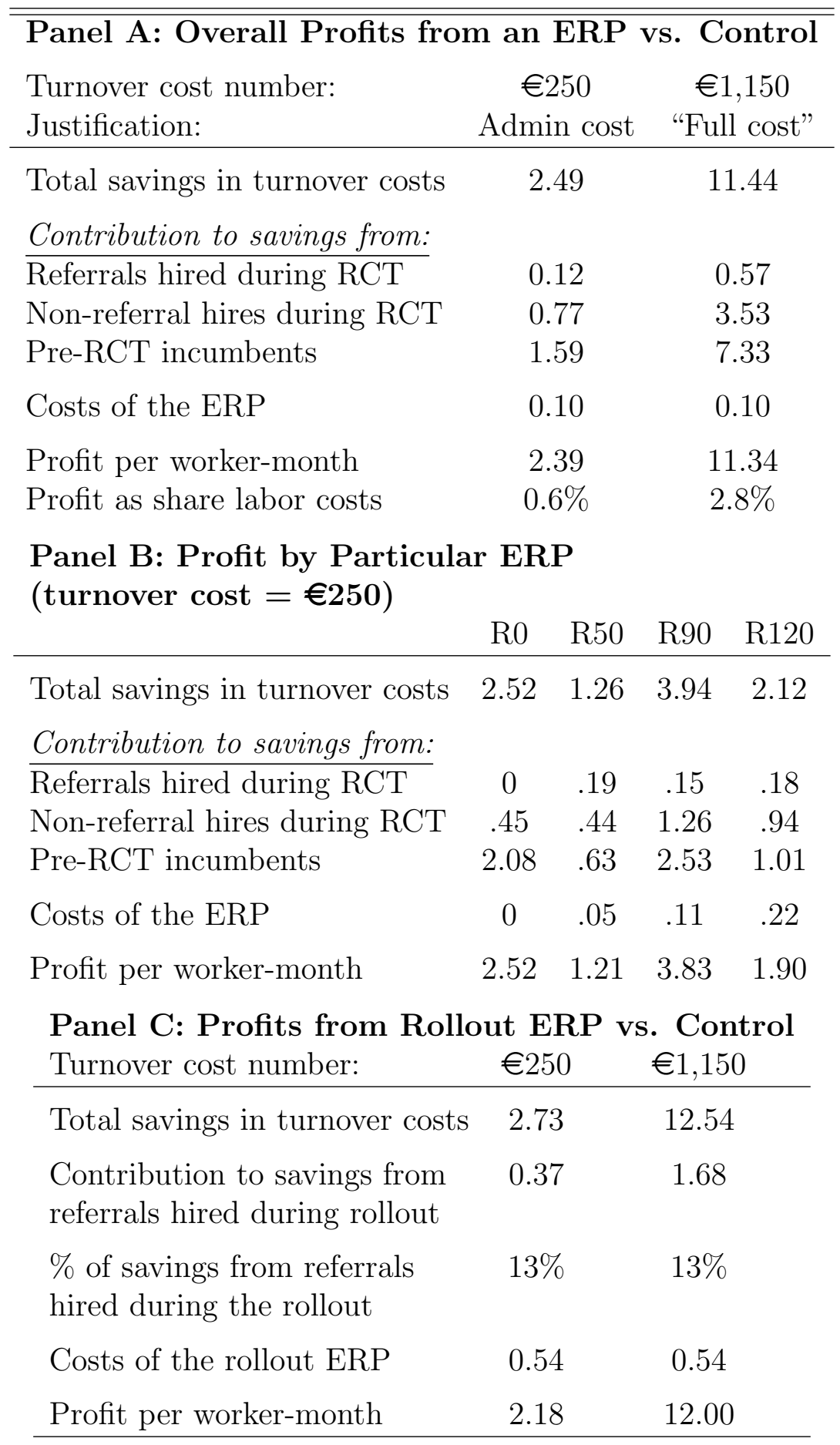

Notes: This table reports profit calculations using the method outlined in Section 5. Panel A reports the profit gains from having an ERP vs. Control, pooling all the RCT ERP treatments together. Panel B reports the profit gains from having one of the particular ERPs compared to Control. Panel C reports the profit gains from having the ERP used in the firmwide rollout (with $€ 30$ on hire and $€ 100$ after 3 months) vs. Control. All numbers are in euros per worker-month. Labor costs are assumed to be $€ 400$ per worker-month. The difference between the "administrative costs" and "full costs" of turnover is that the administrative costs are only the direct costs to hire and train a replacement and do not account for lost productivity, as explained in Appendix A.11. See Appendix A.12 for further details on the profit calculation. 
Table 8: Heterogeneity by Pre-RCT Store Performance, Local Unemployment, and Worker Characteristics: Direct and Overall Effects of Having an ERP

\begin{tabular}{lccccc}
\hline \hline $\begin{array}{l}\text { Characteristic: } \\
\text { (first } 3 \text { are normalized) }\end{array}$ & $\begin{array}{c}\text { Store } \\
\text { performance } \\
\text { index }\end{array}$ & $\begin{array}{c}\text { Attri- } \\
\text { tion } \\
\text { rate }\end{array}$ & $\begin{array}{c}\text { Unemploy } \\
\text {-ment } \\
\text { rate }\end{array}$ & Male & Cashier \\
& $(1)$ & $(2)$ & $(3)$ & $(4)$ & $(5)$ \\
\hline Panel A: Direct Effects. OLS Models, & DV $=$ Hire is a Referral (x100). \\
ERP & $2.32^{* * *}$ & $2.39^{* * *}$ & $2.39^{* * *}$ & $2.67^{* * *}$ & 1.62 \\
& $(0.60)$ & $(0.61)$ & $(0.61)$ & $(0.70)$ & $(1.62)$ \\
ERP X Characteristic & 0.50 & 0.31 & -0.94 & -0.89 & 0.90 \\
& $(0.47)$ & $(0.49)$ & $(0.60)$ & $(1.12)$ & $(1.52)$ \\
Westfall-Young p-vals & $\{0.51\}$ & $\{0.53\}$ & $\{0.33\}$ & $\{0.68\}$ & $\{0.68\}$
\end{tabular}

Panel B: Overall Effects. Cox Models, DV = Worker Attrites in a Month.

$\begin{array}{lccccc}\text { ERP } & -0.13^{* * *} & -0.15^{* * *} & -0.15^{* * *} & -0.10^{*} & -0.26^{* *} \\ & (0.04) & (0.05) & (0.04) & (0.05) & (0.13) \\ \text { ERP X Characteristic } & -0.10^{* *} & 0.03 & 0.10^{* *} & -0.20^{* *} & 0.13 \\ & (0.05) & (0.03) & (0.04) & (0.10) & (0.13) \\ \text { Westfall-Young p-vals } & \{0.07\} & \{0.84\} & \{0.07\} & \{0.04\} & \{0.93\}\end{array}$

$\mathrm{w} /$ linear probability model

Panel C: Reduction in Labor Costs from Having an ERP, Assuming

Turnover Cost of $€ 250$, i.e., "Admin Costs."

Calculated for Stores at p10 and p90 of Various Store Characteristics

$\begin{array}{lcccc}\text { 10th Percentile Stores } & -0.1 \% & 0.6 \% & 1.1 \% & \text { Not applicable } \\ \text { 90th Percentile Stores } & 1.1 \% & 0.6 \% & 0.2 \% & \text { Not applicable }\end{array}$

Panel D: Reduction in Labor Costs from Having an ERP, Assuming Turnover Cost of $€ 1,150$, i.e., "Full Costs." Calculated for Stores at p10 and p90 of Various Characteristics

\begin{tabular}{lcccc} 
10th Percentile Stores & $-0.2 \%$ & $3 \%$ & $5.2 \%$ & Not applicable \\
90th Percentile Stores & $5.3 \%$ & $2.6 \%$ & $1 \%$ & Not applicable \\
\hline
\end{tabular}

Main notes: Standard errors clustered by store are in parentheses. The store performance index is defined in Section 6.

Panel A: Each column is similar to column 3 of Table 3, with the difference being that we add two regressors: ERP X Characteristic and Characteristic. An observation is a new hire during the RCT. $\mathrm{N}=3,811$ except for column 4 where $\mathrm{N}=3,810$.

Panel B: Each column is similar to column 2 of Table 5, with the difference that we add two regressors: ERP X Char and Char. An observation is a worker-month in the RCT among grocery workers. N=74,188 except for column 4 where $\mathrm{N}=74,174$.

Panels $C$ - $D$ : We present the profit gains from having an ERP as a share of firm labor costs, similar to Table 7. The difference is we calculate the profit gains as a share of labor costs for stores at the 10th percentile of a characteristic and at the 90th percentile of a characteristic. Panel $\mathrm{C}$ does the calculation assuming a turnover cost of $€ 250$ (i.e., the administrative cost of turnover), whereas Panel D assumes a turnover cost of $€ 1,150$ (i.e., the full cost of turnover). A positive number is a beneficial treatment effect (i.e., a reduction in labor costs).

Additional notes on inference: To account for multiple hypothesis testing in analyzing treatment effect heterogeneity, the curly brackets display family-wise error rate (FWER) adjusted p-values based on the Westfall \& Young (1993) free step-down procedure (5,000 replications) and while accounting for clustering by store using a clustered bootstrap. In both Panels $\mathrm{A}$ and $\mathrm{B}$, there are two families of tested hypotheses, one for store-level characteristics (in columns 1-3) and one for worker-level characteristics (in columns 4-5). The family of tested hypotheses is the set of 3 or 2 tests about whether the coefficient on ERP X Characteristic equals 0 for the 3 or 2 displayed characteristics. For the Cox proportional hazard models in Panel B, the Westfall-Young p-values are based on linear probability models with the same controls as the Cox models except tenure is controlled for as in Figure 4 instead of nonparametrically. Welse a linear probability model here because Cox is not supported by the 'wyoung.ado' Stata package (Jones et al., 2019) that we use for Westfall-Young. As discussed in footnote 23, attrition results are very similar with Cox and OLS. For multiple hypothesis testing adjustments applied to our baseline overall attrition results in Table 5, please see Appendix A.6. Stars are based on the conventional clustered-by-store standard errors in parentheses, with $*$ significant at $10 \% ; * *$ significant at $5 \% ; * * *$ significant at $1 \%$ 
Table 9: Heterogeneity by Job and by Time Period: Referrals Made as a Share of Hires (Panel A) and the Share of Turnover Savings from Referral Hires (Panel B)

\begin{tabular}{lcc}
\hline \hline & RCT & \multicolumn{2}{c}{ Post-RCT Rollout } \\
\hline Panel A: Referrals & Made as a Share of Total Hires \\
All Grocery Jobs & $3 \%$ & $12 \%$ \\
Cashier & $3 \%$ & $11 \%$ \\
Grocery Non-cashier & $5 \%$ & $17 \%$ \\
Non-Grocery Jobs & & $37 \%$ \\
Panel B: Share of Turnover Benefits from Referral Hires \\
(i.e., the Share of Benefits that are Direct Benefits) \\
All Grocery Jobs & $5 \%$ & $13 \%$ \\
Cashier & $4 \%$ & $12 \%$ \\
Grocery Non-cashier & $12 \%$ & $20 \%$ \\
Non-Grocery Jobs & $35 \%$ \\
\hline
\end{tabular}

Notes: Panel A shows the number of referrals made as a share of total hires by job and period. For example, if there were a job-period where employees made 3 referrals and for which 10 new workers were hired, the number shown would be $30 \%$. Italics are used to indicate that grocery jobs are separated into cashier and grocery non-cashier jobs (e.g., butcher, baker, assistant manager). The time period for the RCT is December 2015-December 2016. The post-RCT period is January 2017-May 2017, and is the period during which the firm rolled out a new ERP to all the firm at once (paying $€ 30$ at hire and $€ 100$ after 3 months). During the post-RCT period, there are 1,079 hires in grocery jobs and about 500 hires in non-grocery jobs. Panel B shows the share of turnover benefits from referral hires. The percentage shown is the direct benefit share, whereas the indirect benefit share is equal to $100 \%$ minus the percentage shown. For example, for grocery non-cashier jobs in the post-RCT ERP rollout, $20 \%$ of the turnover benefits are direct and $80 \%$ are indirect. In both panels, the entry for non-grocery jobs during the RCT is missing because the RCT was restricted to grocery jobs. 